\title{
APPLICATIONS OF SATELLITE 'HYPER-SENSING' IN CHINESE AGRICULTURE: CHALLENGES AND OPPORTUNITIES
}

\author{
Alex Okiemute Onojeghuo ${ }^{1,5,}$, George Alan Blackburn ${ }^{1}$, Jingfeng Huang ${ }^{2}$, Daniel Kindred ${ }^{3}$, \\ Wenjiang Huang ${ }^{4}$ \\ ${ }^{1}$ Lancaster Environment Centre, Department of Geography, Lancaster University, LA1 4YQ, United Kingdom \\ ${ }^{2}$ Institute of Agricultural Remote Sensing and Information Application, Zhejiang University, Hangzhou 310029, \\ PR China \\ ${ }^{3}$ ADAS UK Limited, Boxworth, Cambridge CB23 4NN, United Kingdom \\ ${ }^{4}$ Institute of Remote Sensing and Digital Earth, Chinese Academy of Science, Beijing, Haidian District, Beijing \\ 100094, China \\ ${ }^{5}$ Department of Surveying and Geoinformatics, Nnamdi Azikiwe University, Awka, Anambra State, Nigeria \\ * Corresponding author emails: lexisgis@yahoo.com
}

\begin{abstract}
Ensuring adequate food supplies to a large and increasing population continues to be the key challenge for China. Given the increasing integration of China within global markets for agricultural products, this issue is of considerable significance for global food security. Over the last 50 years, China has increased the production of its staple crops mainly by increasing yield per unit land area. However, this has largely been achieved through inappropriate agricultural practices, which have caused environmental degradation, with deleterious consequences for future agricultural productivity. Hence, there is now a pressing need to intensify agriculture in China using practices that are environmentally and economically sustainable. Given the dynamic nature of crops over space and time, the use of remote sensing technology has proven to be a valuable asset providing end-users in many countries with information to guide sustainable agricultural practices. Recently, the field has experienced considerable technological advancements reflected in the availability of 'hyper-sensing' (high spectral, spatial and temporal) satellite imagery useful for monitoring, modelling and mapping of agricultural crops. However, there still remains a significant challenge in fully exploiting such technologies for addressing agricultural problems in China. This review paper evaluates the potential contributions of satellite 'hyper-sensing' to agriculture in China and identifies the opportunities and challenges for future work. We perform a critical evaluation of current capabilities in satellite 'hyper-sensing' in agriculture with an emphasis on Chinese sensors. Our analysis draws on a series of in-depth examples based on recent and on-going projects in China that are developing 'hyper-sensing' approaches for (i) measuring crop phenology parameters and predicting yields; (ii) specifying crop fertiliser requirements; (iii) optimising management responses to abiotic and biotic stress in crops; (iv) maximising yields while minimising water use in arid regions; (v) large-scale crop/cropland mapping; and (vi) management zone delineation. The paper concludes with a synthesis of these application areas in order to define the requirements for future research, technological innovation and knowledge exchange in order to deliver yield sustainability in China.
\end{abstract}

Key words: Hyper-sensing, high-spatial, temporal, hyperspectral, China, remote sensing, yield sustainability 


\section{Introduction}

The production of food in China is a fundamental component of the national economy and a key driver of agricultural policy. The maintenance of food security in China is a critical issue for the country and this has significant ramifications globally. However, China's ability to sustain and increase crop yield is threatened by the effects of climate change, increasing population, agricultural land loss and competing demands for water (Fan et al., 2012; He et al., 2017; Kang et al., 2017; Wei et al., 2009; Zhao et al., 2008). Notably, the Chinese government has identified the conversion of farmlands to industrial and residential use, particularly across productive agricultural regions of the country, as the major threat to the nation's already inadequate levels of staple cereals production (Lichtenberg and Ding, 2008). According to the office of statistics in China, over 14.5 million hectares of arable land in the country was lost between 1979 and 1995. Though this loss was counterbalanced by an addition of 10.1 million hectares of arable land from reclamation activities, this additional land was of lower quality and located in unsuitable areas incapable of promoting agricultural production (Ash and Edmonds, 1998). Furthermore, several studies have attributed the loss of farmland across China to a combined effect of population growth, rapid economic development, urbanisation, agricultural restructuring, government stimulated conversion of marginal croplands to forests or pastures, natural hazards and land degradation (Ding, 2003; He et al., 2017; Smil, 1999; Tan et al., 2005; Yang and Li, 2000). He et al. (2017) provides background information on the impact of urban expansion on food security in China, particularly from decreased cropland net primary productivity.

With regards to food production, the global importance of China is measured by the capacity of the country's agriculture to support staple food supply for most of its population (approximately $20 \%$ of global population) and the world simultaneously. Based on existing statistics, in 2013 China contributed 19, 17, and $22 \%$ of global rice, wheat and maize production, respectively (FAO, 2014); providing an indication of the country's strategic position in the global food market. However, Fred et al (2014) observed that though the Chinese authorities have policies to encourage domestic production of grain as a means of promoting self-sufficiency, grain exports (particularly for rice, wheat and maize) have declined while imports have consistently risen between 2009 and 2013 (Figure 1). Irrespective of China's global production ratings, the country's level of rice imports increased from 0.6 million tonnes in 2011 to 2.6 million tonnes in 2012 (China Import Export, 2014; Ewing and Zhang, 2013). Ewing and Zhang (2013) attribute this substantive rise in China's rice importation to a combination of factors, namely a rapid rise in consumer demand, over reporting of domestic rice production by government officials, poor transportation links between rice-producing and consuming regions of the country and concerns over safety of domestically produced rice due to high fertiliser contamination levels.

\section{[Figure 1]}

The accelerated agricultural growth rate experienced in China over the years can be attributed to increased yield per unit area rather than expansion of arable or cultivated land (Fan et al., 2012) (Figure 2A). All of the country's key grain crops (rice, maize and wheat) have experienced a steady rise in production and yield over the last 50 years (Figures $2 \mathrm{~B}$ and 2C).

[Figure 2]

Although China has experienced increasing crop yields, it is commonly acknowledged that this has in large part been at the expense of the environment due to inappropriate agricultural practices (Fan et al., 2012). Wasteful production methods in China's agricultural sector have aggravated problems of resource shortage; excessive use of pesticides and fertilisers have led 
to the contamination of soil and water bodies while the unrestricted use of water for crop irrigation has severely depleted aquifers (Zheng, 2015). In particular, the excessive use of nitrogen $(\mathrm{N})$ fertilisers in intensified agriculture across China has generated environmental problems such as atmospheric, soil and water enrichment (Ju et al., 2009b) leading to elevated $\mathrm{NO}_{3}-\mathrm{N}$ concentrations in groundwater and reduced $\mathrm{N}$ use efficiency (Wang et al., 2011). The challenge of maintaining or increasing crop production in an environmentally sustainable manner is further exacerbated by issues such as the effects of climate change (Piao et al., 2010) and pressures on agricultural land use from urbanisation.

For the 12th year in a row, China's "No. 1 Central Document" focused on agriculture and rural issues. The document stresses the importance of agriculture in national socioeconomic development stating that 'a strong agricultural sector is a prerequisite for a strong China'. It called for reforms and innovation in agriculture to speed up the modernisation drive, but emphasised sustainability: "Instead of mainly pursuing high output and relying on resources consumption, China should put equal emphasis on quantity, quality and benefits, and attach importance to competitiveness, technological innovation and sustainable growth" (Xinhua, 2015). One of the five areas of concern highlighted in the document was "accelerating the shift of agricultural development pattern with a focus on agricultural modernisation" (MOA, 2015). Over the last decade, China has focused on advancing space-based solutions to addressing different agricultural and environmental problems. This is demonstrated in the establishment of commissioned agencies charged with space-related research and development, such as: China National Space Administration (CNSA), Chinese Academy of Space Technology (CAST), China Centre for Resources Satellite Data and Application (CRESDA), National Remote Sensing Centre of China (NRSCC) and National Satellite Meteorological Centre/Chinese Metrological Administration (NSMC-CMA). These organisations have been exploiting the capabilities of satellite remote sensing to provide information to support decision making in the agricultural sector at various organisational levels. Such information is unique in its capability to provide repeated and complete coverage for different growing seasons and across multiple scales, spanning from small fields to landscapes and regions. In addition to crop type mapping over large landscapes (Chen et al., 2007b; Esch et al., 2014), satellite remote sensing provides critical data on the physiological state of crops (Meng et al., 2009) and its biophysical or biochemical properties (Haboudane et al., 2004; Jingfeng and Blackburn, 2011). Several studies have demonstrated the potential of utilising remote sensing for monitoring crop phenology and provide valuable inputs for crop growth and yield estimation models (Clevers and van Leeuwen, 1996; Hu et al., 2014; Hua et al., 1998; Kurosu et al., 1995; Li et al., 2014b; Onojeghuo and Blackburn, 2011; Pan et al., 2009; Sankaran et al., 2010; Soria-Ruiz et al., 2010; Zhang et al., 2003). However, whilst satellite data has become part of existing agriculture operation systems, the commonly found mismatch between remote sensing products and the information actually required by farmers has led to a slow take-up of this technology within agriculture in many countries.

In China, the deployment of satellite remote sensing in agriculture is particularly challenging because of the generally small field sizes, demands for multiple within-year cropping, the range of crop species and varieties, high spatial heterogeneity in the environment, extreme climatic variability and a wide range of geographic contexts. This means that a wide range of abiotic and biotic factors can act simultaneously across different spatial and temporal scales to influence crop growth and necessitate agricultural interventions. Satellite 'hyper-sensing' offers new and emerging technologies that allow effective capture of high spatial, high temporal and high spectral resolution data. Hence, it is now timely to undertake an evaluation of the potential contributions of satellite 'hyper-sensing' to agriculture in China, in order to define the requirements for future research, technological innovation and knowledge exchange. 
This paper begins by reviewing existing and forthcoming satellite 'hyper-sensing' missions and assesses existing evidence of potential benefits to agriculture of high spatial, spectral and temporal optical imagery, together with contemporary RADAR systems. This review is placed in the context of current national crop monitoring systems, with emphasis on China. A series of in-depth examples demonstrating the potential of 'hyper-sensing' to addressing key agricultural issues, with emphasis on recent and ongoing research projects, are presented. Finally, the paper synthesises evidence needed to build a system that utilises valuable information from satellite 'hyper-sensing' to support management decisions by Chinese producers as a means of maximising crop yield whilst minimising resource inputs and environmental impacts.

\section{Existing and forthcoming satellite 'hyper-sensing' systems for potential agricultural applications}

\section{1. $\quad$ Spaceborne hyperspectral remote sensing for agriculture}

Advances in hyperspectral remote sensing in agriculture have generated significant enhancements over conventional remote sensing techniques, resulting in improved and targeted modelling of specific agricultural characteristics (Thenkabail et al., 2014). The benefits of spaceborne hyperspectral imagery generated by the Earth Observation (EO)-1 and Proba-1 missions. In a review article, Middleton et al. (2013) comprehensively reviewed the EO-1 mission and discussed the characteristics of the two onboard sensors, Hyperion and the Advanced Land Imager (ALI). Essentially, the paper serves as an introduction to instruments, their capabilities and contributions to science and technology (Middleton et al., 2013) and provides an update on the original review of Hyperion presented by Pearlman et al. (2001). In a review of hyperspectral remote sensing of vegetation, Ortenberg (2011) identified the opportunities of developing spaceborne hyperspectral systems for observations in optical region with higher informational and operational performance thereby greatly enhancing vegetation monitoring capabilities in comparison to the conventional spaceborne multispectral sensors. The paper identifies spaceborne hyperspectral missions that are operational and those planned for future commissioning Ortenberg (2011). Summarised in Table 1 below are characteristics of the key existing and planned spaceborne hyperspectral satellite missions that could be used for agricultural applications in China.

[Table 1]

Several studies have demonstrated the potential of hyperspectral remote sensing in improved and targeted assessment of crop characteristics such as in measuring biophysical and biochemical parameters (Clark and Roberts, 2012; Immitzer et al., 2012), mapping of crop species (Sanchez et al., 2014; Thenkabail et al., 2013), quantifying crop phenology and predicting yield (Pan et al., 2015), evaluating crop requirements for fertiliser applications (Jingfeng and Blackburn, 2011; Yi et al., 2010), detecting crop stress (Liu et al., 2010) and determining crop water requirements (Kang et al., 2003; Lewis et al., (submitted)). While the use of hyperspectral imagery is advantageous in these situations, the challenges of effectively managing the dimensionality of the data and data redundancy are key issues to take into consideration. Considering that hyperspectral images are characterised by numerous spectral bands, their use requires rigorous quantitative analysis and intense image pre-processing processes such as atmospheric and radiometric corrections and data normalisation. Tsai et al. (2007) noted that hyperspectral imagery presents the challenge of effectively managing the large volume and dimensionality of data, which typically requires long processing times and extensive computational resources. A number of feature extraction methods (such as principal 
component analysis (PCA), derivative analysis and wavelet analysis) have been used to reduce data volumes in hyperspectral datasets in advance of further image analysis (Onojeghuo and Blackburn, 2011; Pu and Bell, 2013). Thenkabail et al. (2014) noted that approximately 3 to 8 hyperspectral narrow bands are usually sufficient for building predictive models of crop biophysical variables, and further bands are unnecessary and can contribute signal noise, highlighting the importance of initial feature extraction stages. A number of studies have used hyperspectral vegetation indices to determine and better understand key characteristics of vegetation and agricultural crops (Gitelson, 2013; Haboudane et al., 2004; Pan et al., 2015; Pu and Gong, 2011). Indeed, the potential for using hyperspectral data for specifying crop fertiliser requirements is examined later in section 3.2.

Owing to the detailed spectral information contained in hyperspectral imagery, subtle objects and materials can be recognised and quantified. However, the process of detection, discrimination, classification and quantification with hundreds of very narrow spectral bands comes with its associated challenges such as handling large data volumes, the presence of noise and other complexities associated with data handling, processing and analysis. Unlike the case of multispectral imagery characterised by low spectral resolution, hyperspectral imagery is usually faced with the issue of mixed pixels and sub-pixels generated by subtle spatial changes in the reflectance properties of land surfaces which are detected due to the sensitivity of the hyperspectral sensor. In the case of multispectral imagery, land cover types are easily distinguishable using pattern recognition and classification techniques. However, for hyperspectral imagery objects of interest appear either as a form mixed by a number of material substances or at sub-pixel levels with targets embedded in a single pixel. Hence, a major challenge while working with hyperspectral imagery is that objects of interest can only typically be identified, discriminated, classified, identified, recognised and quantified using target-detection based approaches as opposed to pattern-based multispectral imaging techniques (Dey et al., 2010; Liu et al., 2006; Schürmann, 1996).

Numerous algorithms have been developed for detection and classification in hyperspectral imaging. Two types of information, a priori and a posteriori, representing knowledge provided before processing and obtained during data processing, respectively, can serve as inputs during the classification process. Chang (2007) reviewed two hyperspectral target detection and classification algorithms using sequential filters: an information processed filter (a priori) and a posteriori target information to suppress unwanted interference and noise effects. Three wellknown filter techniques representing algorithms that process different levels of information to enhance performance were analysed. These included Orthogonal Subspace Projection (OSP) (Chang, 2005; Harsanyi and Chang, 1994; Ren and Chang, 2000), Constrained Energy Minimisation (CEM) (Chang, 2003; Farrand and Harsanyi, 1997), and RX-anomaly detection (Kwon and Nasrabadi, 2005; Reed and Yu, 1990; Yu et al., 1993). Chang (2007) noted the following: (1) the OSP requires a complete a priori knowledge, (2) RX-anomaly detection relies only the a posteriori information provided by data samples and (3) CEM requires a priori information on the desired targets used in the matched filter with a posteriori information obtained from data samples to suppress interfering effects while performing target extraction. Hence, the performance of the aforementioned filter algorithms is affected by the information used in their matched signal.

Examples of popular hyperspectral image exploitation methodologies that rely on a mixture of statistically and physically based methodologies are the Optical Real-Time Adaptive Spectral Identification System (ORASIS) (Bowles and Gillis, 2007) and N-FINDR (Winter, 1999; Winter, 2004). Both methodologies are comprised of a number of algorithms designed to perform various tasks in sequence. The first-stage of ORASIS develops a pre-screener that finds an exemplar set and uses such as a code book to encode all image spectral signatures. The 
second-stage projects the exemplar set into a low-dimensional space spanned by an appropriate set of bases. The second-stage low dimensionality reduction operates similarly to PCA (Byrne et al., 1980; Jolliffe, 2002; Singh, 1989). The third-stage process performs a simplex-based endmember extraction to select the desired set of endmembers that are used to form a linear mixing model for least-squares error-based spectral unmixing (Bowles and Gillis, 2007). This is carried out in the fourth and final state process to exploit three applications: automatic target recognition, terrain categorisation, and compression (Bowles and Gillis, 2007). The NFINDER algorithm FINDR (Winter, 1999, 2004) was designed to work on data after dimensionality reduction via subspace projection (Winter, 2007). For this process, the input is the full spectral image cube without dimensionality reduction or data thinning process. The full dataset is examined to find the set of pixels with the largest possible volume. The final output of N-FINDER produces a set of images, each of which shows the fractional abundance of an endmember in each pixel (Winter, 1999, 2004; Winter, 2007).

While not all possible analytical techniques are covered here, this section highlights some of the key challenges associated with analysing hyperspectral imagery and outlines the major solutions that have been developed. This demonstrates the importance of having a good understanding and clear justification for all stages of the analysis and proper management of hyperspectral data in order that such data can be fully exploited. Such approaches are widely applicable but the precise series of pre-processing and processing stages need to be fully validated for each application area within agriculture and this issue requires extensive research before the use of hyperspectral imagery becomes fully operational in any particular application.

\subsection{High temporal optical satellite sensors for agriculture}

Belward and Skøien (2015) noted that at the end of 2013, 197 earth observing polar orbiter were successfully launched and approximately $50 \%$ of these are still operational. Over time, most of these space-borne optical sensors have improved capabilities in acquiring earth observation data with better spatial, spectral, radiometric and temporal resolutions. These advancements have revolutionised the use of multi-temporal remote sensing for time-series analysis and applications (Ban, 2016). In terms of applying high temporal optical satellite sensors to agriculture, research communities are faced with the challenge of balancing out the right temporal resolution of earth observation data with spatial and spectral resolutions for varied applications across different scales. To this end, we aim identify and discuss a number of optical sensors in order of their revisit times in orbit. Table 2 summarises key characteristics of existing, planned and recent decommissioned high temporal optical satellite sensors commonly used for agricultural applications. Based on the repeat cycle, the optical satellite sensors presented in Table 2 are categorised into five broad ranges - daily, 1-4 days, 5-10 days, 11-16 days, and 21-29 days respectively.

The KOMPSAT-2 imagery, with repeat cycles of less than a day, has been used in a number of agricultural-related applications some of which include estimating carbon sequestration in forests (Kim et al., 2009), crop yield prediction (Lee et al., 2011), estimating levels of deforestation (Achard et al., 2010), and agricultural land cover mapping (Lavender, 2016; Lewinski et al., 2010). Lee et al. (2011) generated crop yield prediction models using field spectral reflectance obtained during the growing season of six crops (rice, potato, red pepper, garlic, and bean plants) integrated with multi-temporal KOMPSAT-2 derived vegetation index for small farm locations across part of South Korea. The value of using high temporal optical satellite imagery is further demonstrated in Huang et al. (2017). In this study, the authors investigated the potential of using 1-4 days revisit RapidEye and WorldView-2 optical satellite data combined with field measurements to monitor rice nitrogen status over agricultural fields in Jiansanjiang province, Northeast China. Owing to additional red edge spectral information 
provided by both RapidEye and WorldView-2, as against other conventional four-band multispectral imagery, the authors were able to monitor site-specific nitrogen levels accurately and generate vital information for effective management practices. Another example of optical satellite sensors within the 1-4 days revisit category is the Chinese developed HJ-1 satellite constellation. To better understand the environment and promote environmental protection and disaster reduction, the Chinese government in 2005 approved the project "Environmental and disaster monitoring and forecasting with small satellite constellation (HJ-1)". The key characteristics of the HJ-1 satellites are presented in Table 2. Past studies have discussed in detail the characteristics and use of the HJ-1 satellites. Examples of such pertain to environmental applications (Chen et al., 2011a; Wang et al., 2009; Wang, 2012; Wang et al., 2010b; Wang et al., 2005; Xue et al., 2008) and understanding the image quality of acquire satellite imagery (Li et al., 2012b; Wang et al., 2010b; Zhang et al., 2009a; Zhang et al., 2010). For example, the multispectral data from the HJ-CCD sensor has demonstrated potential in monitoring water quality of inland waters ( $\mathrm{Li}$ et al., 2012b). Since the spectral ranges of the HJ-CDD bands are similar to Landsat bands 1-4 these could be used for diverse agricultural applications such in Zhang et al. (2010) in which the authors used multi-temporal HJ-1 satellite images for wheat planting area estimation. The results of this study demonstrated capabilities of HJ-1 data for regional and parcel scale mapping of wheat crops across the whole of Hebei Province, China. Similarly, Chen et al. (2011a) investigated the use of HJ-1A/B satellite data for monitoring rice cultivation areas in Guangdong province in southern China. Also, Wang et al. (2015a) estimated single-cropped rice planting area under generally fragmented and irregular land cover composition in the south-east plain region using multi-temporal $\mathrm{HJ}-1 \mathrm{~A} / \mathrm{B}$ satellite data and employing two-band enhanced vegetation index (EVI2) temporal signatures. Overall, data from the HJ-1 satellite constellation has shown to possess great potential for monitoring and mapping crop growth in China. However, the challenge of using HJ-1 satellite data is the constrained access to the scientific community outside China. To this end, the use of commercial (such as IKONOS-2, WorldView-2/3, Rapid Eye etc.) or 'open access' data (such as Landsat, MODIS etc.) is more realistic and sustainable approach to obtaining regular multi-temporal optical satellite data for agricultural applications. The Landsat mission, first launched on July 23, 1972, has been followed up with seven additional successfully launches making it one of the most popular sources of multi-temporal optical satellite imagery in the scientific community. With over 44-year achieve of freely available earth observation data, Landsat missions provide to end-users one of the largest depository of historic earth observation data necessary for reconstructing historic changes due to natural or anthropogenic causes at regional and global scales. Dong et al (2016) recently mapped paddy rice planting areas in northeastern Asia with Landsat 8 images, phenology-based algorithm and Google Earth Engine. The phenology and pixel-based paddy rice mapping algorithm used in the study was able to identify paddy rice planting areas with spatial resolution of $30 \mathrm{~m}$ over parts of Japan, North Korea, South Korea, and Northeast China. Similarly, Zhou et al (2016) mapped paddy rice planting area in rice-wetland areas of the Panjin Plain in China through analysis of Landsat 8 OLI and MODIS images. The results of the study demonstrate the potential of the phenology-based paddy rice-mapping algorithm, through integrating MODIS and Landsat 8 OLI images, to map paddy rice fields in complex landscapes of paddy rice and natural wetland in the study area. The sole use of only Landsat time-series imagery (Dong et al., 2015; Mei et al., 2016; Xu et al., 2016; Zhu et al., 2016) or in combination with similar optical satellite sensors such as MODIS or Sentinel-2 has become common practice in agricultural applications in recent times (Novelli et al., 2016; Sibanda et al., 2016). Zhang et al. (2017) recently mapped the annual paddy rice planting areas for China and India from 2000 to 2015 using time series MODIS data and a phenology-based rice algorithm. The authors also investigated the spatiotemporal changes in paddy rice fields in both countries from the perspective of location, 
climate and elevation. Based on the changes observed, the authors were able to provide valuable information on how these observed changes could affect national food security, climate change, environmental issues, and biodiversity. In another study, Clauss et al. (2016) used MODIS time-series data and a one support vector machine learning algorithm to map paddy rice field areas in continental China for the years 2002, 2005, 2010 and 2014 at 250-m resolution. Another viable option for sourcing high temporal optical satellite data is the ESA Sentinel-2 mission (Aschbacher and Milagro-Pérez, 2012; Berger and Aschbacher, 2012; Delegido et al., 2011; Drusch et al., 2012). Delegido et al (2011) evaluated the potential use of Sentinel-2 data (particularly the red edge bands) for empirical estimation of green LAI and chlorophyll content (two key vegetation biophysical parameters) and successfully demonstrated the possibility of estimating valuable plant biophysical parameters based on generic vegetation indices.

Following the availability of high temporal optical satellite data, several techniques and processing algorithms have been developed for change detection (Islam et al., (in press); Leichtle et al., 2017; Lu et al., 2004; Yuan et al., 2005) and time-series analysis (Galford et al., 2008; Jönsson and Eklundh, 2004; Pinzon and Tucker, 2014). The application of such image analysis techniques is demonstrated in a range of applications such as crop monitoring (Delbart et al., 2017), vegetation dynamics analysis (Park et al., 2017) and land cover mapping (Fieuzal et al., 2017). Apart from most commercial optical satellite sensors, most frequent open access satellite images with reasonable revisit times (as shown in Table 2) have rather coarse spatial resolutions (such as MODIS - 250 to $1,000 \mathrm{~m}$ and AVHRR - $1.09 \mathrm{~km}$ at nadir). This makes such coarse satellite sensors incapable of detecting variability at fine scales owing to mixed pixel effects. In such cases, a single pixel in the image may cover two or more fields or management units (Peng et al., 2011). Hence, there is limited capacity to use such coarse data to provide crop growth information at the localised scale that is appropriate to farmers. Recent studies have suggested the use of spatio-temporal fusion techniques to provide more regular finer spatial and temporal resolution by fusing MODIS with other sensors like Landsat and Sentinel-2 which have revisit times of 16 and 12 days respectively (Gao et al., 2006; Wang et al., 2017). Gao et al. (2006) proposed a Spatial and Temporal Adaptive Reflectance Fusion Model (STARFM) to fuse Landsat and MODIS data. This technique has been successfully used in several studies (Gao et al., 2017; Song and Huang, 2013; Zhu et al., 2017). Zhu et al. (2017) evaluated the applied STARFM algorithm to fusing Landsat images with MODIS Nadir Bidirectional Reflectance Distribution Function Adjusted Reflectance data for crop-type classification. Using available Landsat and MODIS images over the study area from 2010 to 2014, downscaled Landsat-like images at 8-day interval were used as inputs in the mapping process. In a similar approach Gao et al., (2017) assesed the use of Landsat-MODIS data fusion results over cropland to map crop phenology at $30 \mathrm{~m}$ resolution with fused surface reflectance data. A major limitations of optical satellite sensor imagery is the frequent occurrence of scenes contaminated by cloud cover, snow, and shadow overcasts (Asner, 2001; Costa and Foley, 1998). Radar imagery, which is unobstructed by clouds, has been successfully employed in numerous agricultural studies. Additional details of radar satellite data in agricultural applications are presented in section 2.4 of this paper.

[Table 2]

\subsection{High spatial optical satellite sensors for agriculture}

Agricultural production systems have benefited greatly from the integration of technological advancements such as mechanisation, synthesised fertiliser applications, and genetic engineering. All these are integral components of precision agriculture, a re-organised system of agriculture that performs at high-efficiency, low input, and adopts a sustainable approach to 
agricultural practice. Precision agriculture benefits from the convergence of several technologies such as geographic information system, global positioning system, remote sensing, mobile computing, telecommunication, and advanced information system (Gibbons, 2000). Harmon et al (2005) stated that precision agriculture utilises large amount of data processed in time and space in order to make more effective use of farm inputs which in turn results in improved crop production and environmental quality. Over time the emphasis of precision agriculture is the use of spatiotemporal data analysis and effective management practices rather than the use of only spatial data analysis and management (Li et al., 2005; Varvel et al., 1997; Xiang et al., 2007). The advancements in technology, especially in remote sensing, has facilitated the availability of high spatial optical sensors capable of providing satellite imagery with sufficient spectral information for use in a wide range of agricultural applications. The agricultural industry is now capable of acquiring more comprehensive information on production variability in both space and time at finer resolutions in comparison to past practices (Zhang et al., 2002). In a comprehensive review study on the role of remote sensing application in precision agriculture, Mulla (2013) noted that as spectral resolution of satellite imagery has improved over time so has the suitability of using reflectance data from platforms increased for precision agriculture applications (optical sensors in particular). Listed in Table 3 are characteristics of commonly used high spatial optical satellite sensors used in agricultural applications. The selection of optical satellite imagery with appropriate spatial and spectral resolutions for precision agriculture applications is usually dependent on a number of factors such as crop management objectives, spatial extent of farm unit area, and capacity of farm equipment to vary farm inputs (such as fertiliser application, insecticide administration etc.). The estimation of spatial patterns in crop biomass monitoring or yield estimation usually require high spatial (1-3 metres) and spectral resolution data as demonstrated in previous studies (Coltri et al., 2012a; Li et al., 2012a; Ramoelo et al., 2015).

The advent of optical satellite imaging systems, such as IKONOS and QuickBird, both with high spatial resolution and quick revisit times has contributed immensely to precision agriculture. Using spectral information contained in the visible and near infrared bands of IKONOS imagery, Seelan et al. (2003) identified nitrogen (N) deficiencies in sugar beet and determined the fungicide performance efficiency in wheat and field sites that had inadequate artificial drainage in wheat. Similarly, Bausch and Khosla (2010a) used QuickBird imagery derived estimates of normalised green normalised difference vegetation index (NGNDVI) to establish the existence of strong correlation with spatial patterns in nitrogen sufficiency in irrigated maize. The introduction of additional spectral information such as the red edge spectral wavelength contained in WorldView-2 has further enhanced the processing capability and application to precision agriculture. Li et al (2014a) evaluated the performance of simulated WorldView- 2 red-edge based spectral indices for estimating plant $\mathrm{N}$ concentration and uptake of summer maize (Zea mays $L$ ). The authors also analysed the influence of bandwidth and crop growth stage changes on the performance of four red edge-based indices namely, canopy chlorophyll content index (CCCI), MERIS terrestrial chlorophyll index (MTCI), normalized difference red edge (NDRE) and red edge chlorophyll index (CIred edge). All four red-edge indices performed better than the conventional normalized difference vegetation index (NDVI) and ratio vegetation index (RVI) for estimating plant $\mathrm{N}$ uptake. In addition to the afore mentioned application of commercial high resolution optical satellite data there are new opportunities for crop mapping and assessment (Drusch et al., 2012; Esch et al., 2014; Hornacek et al., 2012; Li et al., 2013; Pan et al., 2009; Qiu et al., 2014; Turker and Ozdarici, 2011; Yang et al., 2006; Yang et al., 2011), identifying and better understanding biophysical characteristics of plant species (Coltri et al., 2012b; Delegido et al., 2011; Gonsamo, 2010; Hornacek et al., 2012; Kerr and Ostrovsky, 2003; Ramirez and Zullo Jr, 2010) and monitoring agricultural activities (El Hajj et al., 2009; Sawaya et al., 2003). Other 
application of high spatial resolution optical satellite data to agriculture in China include crop classification for estimating crop acreage or production (Jia et al., 2012; Jia et al., 2013; Wang et al., 2010a; $\mathrm{Wu}$ and $\mathrm{Li}, 2012$ ), delineation of agricultural management zones (Guo et al., 2013; Li et al., 2005; Li et al., 2007; Song et al., 2009; Xiang et al., 2007; Xin-Zhong et al., 2009) and mapping of crop patterns (Cai and Cui, 2009; Liping et al., 2007; Wu et al., 2004). Given that the average holding of land across is approximately 0.5 hectares, the availability of optical satellite data high spatial detail and sufficient spectral information for vegetation analysis is critical for agricultural applications.

In addition to the commercial optical high spatial resolution satellite data, the Chinese have developed several sensors that could be used in agriculture applications. The Chinese highspatial-resolution satellite, Ziyuan-3 (ZY-3), developed to perform land resource surveys and monitoring particularly for agriculture (Lin et al., 2013) is equipped with a $2.1 \mathrm{~m}$ resolution panchromatic sensor and a $5.8 \mathrm{~m}$ resolution multispectral sensor (Table 3). A comprehensive review (Tang and Xie, 2012) and assessments (Li et al., 2014c; Lin et al., 2013; Tang and Xie, 2012) of the ZY-3 satellite images are available, but there has been insufficient literature verifying the quality of ZY-3 satellite imagery. Tang and Xie (2012) noted that development of satellite surveying and mapping technology in China is still limited compared to advanced global standards. They further added that China lacks a large-scale, reliable and accurate data processing system capable of effectively managing satellite applications. Tang and Xie (2012) recommend that research of key techniques, such as high-resolution sensor manufacture and testing, precise attitude determination, precise orbit determination, and in-flight geometric and radiometric calibration be strengthened by the Chinese. Other Chinese satellites with high spatial resolution sensors are Gaofen-1 and 2 (GF-1 and 2) of the China National Space Administration (CNSA). These are part of the civilian High Definition Earth Observation Satellite programme, which was proposed in 2006 and approved by government in 2010 . The GF-1 satellite was launched on 26 March 2013 and has three CCD cameras that generate a $2 \mathrm{~m}$ resolution panchromatic band, 3 visible and near infrared bands of $8 \mathrm{~m}$ resolution and 3 visible and near-infrared bands at 16m (Wei et al., 2009; Zhao et al., 2008). Wang et al. (2014) mapped the extent of cotton area in Xinjiang, China using multi-sensor (MODIS, Landsat 8, HJ-1, and GF-1) satellite data. In this study, the GF-1 high spatial resolution satellite data was used to validate the cotton maps derived using multi-temporal NDVI image from Landsat 8 and HJ-1. The validation procedure produced an overall accuracy of $83.8 \%$. The GF-2 spacecraft was launched on August 19, 2014 on a CZ-4B (Long March 4B) vehicle from the Taiyuan Satellite Launch Centre in China. Shen et al. (2017) successfully monitored grasslands using the Chinese GF-2 HD satellite across Jiuquan city, Gansu province, China.

[Table 3]

\subsection{RADAR based satellite sensors for agriculture}

Synthetic Aperture Radar (SAR) satellite systems transmit at frequencies of around $1 \mathrm{GHz}$ to $10 \mathrm{GHz}$ and measure the backscatter signals to generate microwave images of the earth's surface at high spatial resolutions (ranging from 10 to 100 metres) (CEOS, 2015). Since SAR systems have ability to penetrate through clouds and can operate day or night, they are a valuable resource for agricultural monitoring. In particular, SAR data have been applied for agricultural mapping and monitoring (CEH, 2016; Yonezawa et al., 2012) and measurement of crop biophysical properties (Harrell et al., 1997; McNairn and Brisco, 2004; Vyas et al., 2003). Krieger and Moreira (2006) highlight the potential and challenges of space-borne bi- and multistatic SAR sensors and evaluated their potential for applications such as frequent monitoring, wide-swath imaging, scene classification, single pass cross-track interferometry and resolution enhancement. A detailed review of the spaceborne imaging radar C/X-Band 
synthetic aperture radar (SIR-C/X - SAR) missions and its applications was provided by Evans et al. (1997). Subsequently, Evans (2006) reviewed the changes in SIR-C/X-SAR instrumentation and applications from 1996 to 2006. The article suggests that the multifrequency, multi-polarisation capability provided by SIR-C/X-SAR was unsurpassed by any spaceborne system, making the data set valuable for algorithm development and assessment of optimal imaging parameters (Evans, 2006). A similar review on the applications and challenges of using radar data for earth observation was also provided by Palmann et al. (2008). Table 4 summarises characteristics of suitable SAR satellite systems for agricultural applications.

Various research performed with synthetic aperture radar (SAR) satellite systems such as European Remote Sensing Satellites Sentinel-1 series, Canadian Space Agency RADARSAT2 , and Chinese $\mathrm{HJ}-1 \mathrm{C}$ are demonstrated to have varied and useful applications in agricultural monitoring. These $\mathrm{C}$ band RADAR based spaceborne satellites varied combinations of single and dual polarisation channels has shown to be of immense value in agricultural developments such as crop-type mapping and condition assessment, soil tillage and crop residue mapping, and soil moisture estimation (McNairn and Brisco, 2004). The RADARSAT-2 satellite system is capable of simultaneously acquiring two polarizations in the selective dual polarisation mode. These include the one like-polarization and one cross-polarization ( $\mathrm{HH}$ and $\mathrm{HV}$; or VV and $\mathrm{VH}$ ) and quad polarisation mode in which both the amplitude and phase of the four linear polarisations (HH, VV, HV, and VH) are measured (McNairn and Brisco, 2004). Jiao et al. (2014) mapped and monitored crops with 19 RADARSAT-2 fine beam polarimetric images of an agricultural area in North-eastern Ontario, Canada using object-oriented classification approach. In comparison to a single-date SAR object-classification approach, the multi-date RADARSAT-2 approach outperformed the latter and accurately identified the five key agricultural crops in the region which included wheat, oat, soybean, canola, and forage. Similarly, Liu et al. (2013) assessed the feasibility of monitoring crop growth based on a trend analysis of three elementary radar scattering mechanisms using three consecutive years (20082010) of RADARSAT-2 Fine Quad Mode data for a test located in Eastern Ontario, Canada. The temporal evaluation of the intensity of the scattering mechanisms obtained from the multitemporal RADARSAT-2 data tracked the measured leaf area index and phenological plant development of the crops investigated. The changes in growth stage were crop type specific, thus demonstrating the versatility of this approach for effective crop monitoring using radar based information. In this study, it was noted that when harvest occurs, the backscatter intensities change significantly, and these changes aid in identifying crops. A crop map was produced by applying the maximum likelihood classification to the multi-temporal RADASAT-2 images, achieving an overall accuracy of $85 \%$. In addition to crop mapping, RADARSAT-2 data has demonstrated to be of immense value in soil moisture mapping (McNairn et al., 2012; Merzouki et al., 2011). Chai et al. (2015) estimated volumetric soil moisture of plateau pasture using fully polarimetric C-band RADARSAT-2 SAR images. A similar spaceborne radar system capable of soil moisture measurement is onboard the first satellite of the Sentinel constellation, Sentinel-1. The C-band SAR sensor on Sentinel-1 has demonstrated immense potential for global mapping of surface soil moisture (Hornacek et al., 2012). Son et al. (2017) assessed the performance of two machine learning algorithms (support vector machine and random forests) for rice crop classification using multi-temporal Sentinel1A data. The results indicated that the smooth VH backscatter profiles reflected the temporal characteristics of rice-cropping patterns in the study region. The authors concluded that though both machine learning algorithms were effective in paddy rice field mapping, the random forests classification approach outperformed the support vector machine algorithm. The results reaffirmed the government's rice area statistics with the relative error in area values of $0.2 \%$ (random forests) and 2.2\% (support vector machine) respectively. Nguyen et al. (2016) used Sentinel 1A time series acquired in the dual-polarized $(\mathrm{VV} / \mathrm{VH})$ interferometric wide swath 
mode during the spring growing season (October 2015 to March 2016) in the Mekong Delta to analyse the relationship between the growing cycle of rice plants and the temporal variation of SAR backscatter at different polarizations. The results indicated that the $\mathrm{VH}$ polarisation channels were more sensitive to detecting changes in the rice crop growth cycle and would prove most beneficial to mapping paddy rice fields on a regional scale.

Another spaceborne SAR system of interest is KOMPSAT-5 developed by the Korean Aerospace Research Institute, technical details and specifications of which are presented by Sang-Ryool (2010), Shin et al. (2010), Yoon et al. (2011) and Byoung-Sun et al. (2011). Data from the KOMPSAT-5 SAR system have been used in several applications such as soil moisture detection (Singh et al., 2011; Yisok et al., 2010, 2011), crop identification across complex landscapes (Hoang et al., 2011), land cover classification (Kressler et al., 2003) and disaster monitoring (Duk-jin, 2011; Wu et al., 2005). Similarly, the study by Hoang et al. (2011) demonstrates the potential of using RADARSAT-2 C-band polarimetric images to identify rice fields precisely. Tian et al. (2010) investigated the performance of four spaceborne multi-parameter SAR systems (namely Envisat ASAR, TerraSAR-X, ALOS PALSAR, and RADARSAT-2) for crop mapping in part of South China. The results showed L-band SAR can uniquely discriminate mulberry from other crops (such as maize and vegetable) while C-band SAR could effectively map rice crops with mapping accuracy of $75-80 \%$. In a similar study, TerraSAR-X and RADARSAT-2 were successfully used for crop classification and acreage estimation using the X-band data in part of Canada (McNairn et al., 2009b). The X-band data was able to identify pasture-forage, soybeans, corn and wheat with accuracies of $95 \%$ after post-processing. Bargiel and Herrmann (2011) also demonstrated the potential of utilising multi-temporal high resolution TerraSAR-X Spotlight data for mapping a variety of mixed crops across diverse study areas. Furthermore, the results of Anguel et al. (2010) showed that by using TerraSAR-X data to study bare agricultural fields, local variations in soil moisture can be retrieved effectively. A detailed review of the Italian funded COnstellation of small Satellites for Mediterranean basin Observation (COSMO-SkyMed) mission by Covello et al. (2010) illustrates the benefits of this system in providing commercial products and services for agricultural applications alongside environmental risk management. COSMO-SkyMed imagery have been successfully used in the retrieval and monitoring of vegetation parameters over agricultural land (Santi et al., 2012), land use discrimination and land change detection analysis (Shu-cheng et al., 2011), risk management applications (Battazza et al., 2012), and rice crop growth monitoring (Corcione et al., 2016).

Kramer and Cracknell (2008) discussed the potential use of different spaceborne small satellite sensors, such as the Chinese Environment and Disaster Monitoring Satellites constellation (HJ1), for remote sensing applications. As part of this constellation, the HJ-1C satellite has a fourlook S-band SAR onboard and is designed for frequent monitoring of soil moisture dynamics and other environmental variables (Du et al., 2010b; Guo, 2012). Chen et al. (2005) developed an algorithm for soil moisture change estimation by using HJ-1C S-band VV polarization simulated backscattering-data based on integral equation model. Similarly, Du et al. (2010a) developed a soil moisture retrieval algorithm for the HJ-1C S-band SAR data. Zhang et al. (2009b) demonstrated the feasibility of mapping paddy rice planting areas in Zhejiang Province, southeast China using high-resolution ALOS/PALSAR images acquired at three rice growing stages (transplanting, tillering, and heading). By applying the Support Vector Machine learning algorithm as a classifier, paddy rice fields were accurately mapped across the study area by utilising backscatter polarisation data contained in the multi-date ALOS/PALSAR SAR imagery. The high overall accuracy (kappa value of 0.87 ) demonstrated the value of utilising ALSO/PALSAR data in rice crop mapping. In a similar study, Yusoff et al. (2017) investigated the use of ALOS-1 and 2 (Advanced Land Observing Satellite-1 and 2) PALSAR (Phased 
Array L-band Synthetic Aperture Radar) images for the identification and classification of abandoned agricultural crop areas in parts of Malaysia. The findings of the study showed that PALSAR offers vast possibilities in understanding in detail phenology of agricultural land in tropical vegetation.

Given the increasing availability of optical and radar remote sensing data, research focused on exploiting the complementarity of the information they provide to study land properties is fast gaining considerable pace (Joshi et al., 2016). Studies that have explored the use of radar and optical fused data as against the use of single data sources report improved mapping performance (Kussul et al., 2012; Mansaray et al., 2017; McNairn et al., 2009a; Torbick et al., 2017a). In particular, the fusion of radar and optical satellite data has shown to significantly improve the discrimination and classification of agricultural crops (Blaes et al., 2005; CEH, 2016; Hua et al., 1998; Sandholt, 2001; Soria-Ruiz et al., 2010). The Centre for Ecology and Hydrology $(\mathrm{CEH})$ in collaboration with Remote Sensing Application Consultants Limited have developed methods for wide area crop mapping using Sentinel-1 C-band SAR and Sentinel-2 optical data (CEH, 2016). Using a time-series of Sentinel-1 data (more than 350 individual images over the entire crop-growing season) the 2015 crop map of the entire UK was generated and plans are in place to incorporate Sentinel-2 optical data for national crop mapping in subsequent years. Additional information on the physiological state of crop canopies, such as provided by Sentinel-1 backscatter intensities, has shown to be of valuable contribution to optical spaceborne satellite images such as Landsat, MODIS, and SPOT. Torbick et al. (2017a) produced an updated land use land cover map with fused radar and optical information contained in Sentinel-1A, Landsat-8 OLI, and PALSAR-2 data; all of which were classified with a random forest classifier algorithm. The classification accuracy results were considerably high and demonstrated the effectiveness of such an approach. In addition to rice crop mapping, time series phenological analyses of the dense Sentinel-1 data were executed to assess rice information across all of study area. Singh et al. (2011) also demonstrates potential of fusing information from SAR and optical satellite data for retrieving soil moisture data for vegetated areas with minimum a priori information.

One of the key challenges of spaceborne scatterometer observations is the coarse resolution of the images (Steele-Dunne et al., 2017). However, through the use of spatial resolution enhancement (Long and Hardin, 1994; Long et al., 1993), data assimilation (Mahfouf, 2010), and downscaling approaches (Wagner et al., 2008) new opportunities now exist to perform agricultural applications at field-scale levels. This would be most beneficial in countries like China where numerous farms are held by individual owners. In the past one of the key challenges of spaceborne SAR imagery for agricultural application is limited availability of satellites with reasonably high spatial and temporal resolutions. However, the recent launches of HJ-1C (daily revisit time), Cosmo Sky-Med (4-day revisit time), and Sentinel 1A and 1B (6-day revisit time) has greatly improved temporal coverage. Irrespective of advances in more frequent spaceborne SAR imagery, satellite with sufficiently high spatial and temporal resolutions is limited. Though the Chinese HJ-1C C-band SAR sensor has a daily revisit time and spatial resolution of 5 metres, the access to such HJ-1C data is highly constrained and not open the public. Hence, most monitoring systems utilise the fusion of spaceborne radar and optical imagery approach for varied agricultural applications. The complexity of SAR scattering makes analysis radar imagery for agricultural monitoring a more difficult process compared to popular optical image processing. To facilitate the use of SAR imagery for agricultural applications user community participation and capacity-building activities are recommended to ensure radar products are provided to end-users in a useable format.

[Table 4] 


\subsection{Remote sensing based national/global crop monitoring systems}

A number of individual countries, including China, and trans-national organisations, such the European Commission and the Food and Agriculture Organisation of the United Nations, have crop systems established to monitor regional, national or global crop production. Table 5 gives a summary of national agricultural monitoring systems in Argentina (Fontana et al., 2006), Brazil (http://www.conab.gov.br/), Canada (Korporal et al., 1989; Reichert and Caissy, 2002), United States (Becker-Reshef et al., 2010; Zakzeski et al., 2013), India (Dadhwal et al., 2002; Panigrahy et al., 1997; SAC, 1995) and China (Chen et al., 2011a; Huang et al., 2010; Teng et al., 2012; Wu et al., 2013; Wu et al., 2010). As indicated in Table 5, a common factor amongst these national monitoring systems is the use of satellite remote sensing data and conventional data processing techniques for extracting key information on agricultural crops (such as crop acreage, crop yield estimation, drought estimates and crop phenology).

In this paper, emphasis on discussion of monitoring systems shall be centred on the Chinese monitoring system. China has a number of crop monitoring systems such as the China Agriculture Remote Sensing Monitoring System (CHARMS) and CropWatch. CHARMS was initiated in 1998 and became operational in 1999. It carries out monitoring of crop acreage, drought dynamics and crop growth pattern across agricultural regions of China through use of remote sensing data and soil moisture data (Chen et al., 2011a; Chen et al., 2011b; Huang et al., 2010; Teng et al., 2012). The CropWatch system was designed to assess national and global crop production by mainly using remotely sensed data (from Chinese and other systems) and with little reliance on ground assessments or field monitoring data (Wu et al., 2013; Wu et al., 2010). Examples of satellite data used include HJ-1 CCD (30 metres), Landsat TM / ETM+ (30m), IRS P6 AWIFS (1000m), TERRA / AQUA MODIS $(1 \mathrm{~km})$, NOAA AVHRR $(1 \mathrm{~km})$ and RADARSAT-1 (30 metres), demonstrating the capacity and need to incorporate data from a wide range of different systems.

In addition to the CropWatch global crop monitoring system, the CropWatch agroclimatic indicators (CWAIs) was recently designed to assess the impact of rainfall, temperature and photosynthetically active radiation (referred to as RAIN, TEMP and PAR, respectively) on agriculture at different scales, in combination with other remote-sensing based indicators (Gommes et al., 2017). Gommes et al. (2015) noted that these CWAIs are usually estimated over sub-national administrative units, countries, major food producing zones and large and relatively homogeneous global monitoring and reporting units. The CropWatch agroclimatic indicators (CWAISs) constitute a coherent set of variables that can be used synchronically and diachronically to assess the impact of rainfall, temperature and photosynthetically active radiation on agriculture. Gommes et al. (2017) stated that though CWAISs act as actual climatic variables they constitute at the same time value-added variables designed to focus on areas with the highest agricultural production potential. Hence, they can be computed for any area and for any time period making such information suitable for cross-sector analyses involving socio-economic data and environmental data, including applications in food security, crop monitoring, index-based crop insurance and risk assessments. Asides from the context of global crop monitoring for early warning, the CWAIs could be adapted for other applications such as disaster risk mitigation, index-based crop and livestock insurance, rangeland monitoring, and area-yield index insurance.

Though the afore-mentioned Chinese monitoring systems utilise remote sensing data combined with conventional methods to monitor crop production across different regions of the country, these existing systems largely fail to address issues of farm management practices at localised levels. This is a particular problem because in many regions of China there are very large numbers of small land holdings where agricultural management practices are extremely diverse 
spatially and temporally, meaning that national-scale monitoring programmes have relatively little value for informing sustainable intensification practices locally.

[Table 5]

\section{Agricultural applications of 'hyper-sensing' in China}

\subsection{Measuring crop phenology parameters and predicting yield}

In the context of monitoring agricultural practices, the quantification of crop phenology allows for improved and accurate classification of crops and estimation of crop yields (Meng et al., 2009). Specific dates associated with the crop life cycle are essential to understanding key activities like irrigation scheduling, fertiliser management, crop productivity evaluation and analysis of carbon dioxide exchanges across different ecosystem (Sakamoto et al., 2005). Crop phenology information such as the Start of Season and End of Season parameters can be extracted using temporal profiles of remotely-sensed vegetation indices as demonstrated by Sakamoto et al. (2005). In the study, the authors developed a method to define thresholds for identifying SoS and EoS for 43 different agricultural zones in China by using AVHRR derived NDVI data at 15 days temporal resolution (Sakamoto et al., 2005). After data pre-processing, the NDVI time-series was used to generate a series of parameters such as the slope of the NDVI curve and difference between the NDVI value and a base NDVI value for bare land without snow (Sakamoto et al., 2005). Results of the study demonstrated that using the NDV difference and slope threshold method produced significantly more accurate outputs for the phenology parameters compared to other methods. However, the method is limited given that the precise threshold values need to be re-established periodically.

Using highly frequent satellite data time-series permits accurate mapping of crop phenology. Such information can be used to guide the agricultural community on optimal planting or harvesting times, and develop efficient systems for monitoring crop annual / seasonal variability or drought monitoring (Boschetti et al., 2009; Li et al., 2014b; Meng et al., 2009; Pan et al., 2015; Ren et al., 2008). The study conducted by Pan et al. (2015) utilised multitemporal Chinese HJ-1 A/B CCD satellite images (all year round images of 2011 - 2013) to construct NDVI time-series datasets for cropland area analysis. Given the high temporal capability of the HJ-1 A/B CCD satellite imagery, it was possible to capture the growth trajectories of the summer corn and winter wheat crops grown within each year. Information on phenology parameters for croplands were extracted from satellite data derived NDVI timeseries using the TIMESAT method of (Jonsson and Eklundh, 2004). The results showed that crop season start / end derived from the NDVI time-series are comparable with local agrometrological observations (Pan et al., 2015). Wang et al. (2015b) extracted the phenological parameters of single-cropped rice by integrating HJ-1 CCD and Landsat-8 operational land imager (OLI) data to construct higher temporal resolution vegetation indices (VIs) time-series. When validated against field-observed phenological parameters, the VI time-series had a relative lower root mean square error, and EVI2 showed higher accuracy compared with NDVI. Constructing time-series remote sensing data has been shown to be an effective means of mapping and monitoring crop phenology for farmlands on large scales across China. For example, Boschetti et al. (2009) conducted a study on the use of a time series of 5 years of MODIS NDVI 16-day composites (over 2001-2005) to provide phenological information on rice cropping systems. These data were analysed with TIMESAT system to retrieve key phenological information such as the start of season (emergence), peak (heading) and end of season (maturity). Such studies demonstrate the potential of using high temporal resolution satellite imagery for monitoring crop status and phenology over large scales with minimal field 
verification. Such an approach would prove most beneficial where large surface areas need to be assessed, as is the case with China.

Based on the reviewed case studies, the application of hyper-sensing to measuring yield and crop phenology parameters shows the varied use of multi-temporal medium to coarse spatial resolution and high temporal resolution satellite data to effectively monitor crop growth over specific periods of time. In terms of methodological approaches, a common image processing technique used for crop phenology extraction and interpretation using remote sensing outputs is the Savitzky-Golay (S-G) filter (Chen et al., 2004; Savitzky and Golay, 1964; Schafer, 2011). The S-G filter, usually applied to VI outputs (such as NDVI, EVI or EVI2), allows for the removal of noise introduced by cloud or snow contamination contained in the satellite data. The S-G filter algorithm allows data smoothing without forcing a given mathematical function to fit the data time series thereby reducing the creation of artefacts (Boschetti et al., 2009; Chen et al., 2004; White and Nemani, 2006). Following the filtering, key phenological information can be extracted from VI temporal profiles using automated methods. In most of the case studies reviewed (Boschetti et al., 2009; Pan et al., 2015; Wang et al., 2015b) the open source TIMESAT program (Jonsson and Eklundh, 2004) was employed. Hence, alongside a common pattern of use of data from particular satellite systems, there are a series of analytical procedures that are becoming widely adopted in order to monitor crop phenology.

\section{2. $\quad$ Specifying crop fertiliser requirements}

Monitoring leaf nitrogen status (or leaf nitrogen accumulation) for crops like rice and wheat, both staple crops in China, can assist in providing precise diagnosis and efficient management of plant $\mathrm{N}$ nutrition alongside ensuring accurate prediction of yield formation and $\mathrm{N}$ flow for double cropping systems (such as rice-wheat rotation system) (Feng et al., 2008; Zhu et al., 2008). The use of hyperspectral data to estimate nitrogen concentration (Stroppiana et al., 2009) and monitor leaf nitrogen status (Feng et al., 2008) holds considerable potential for evaluating crop fertilizer requirements. The excessive use of $\mathrm{N}$ fertilisation in intensive agricultural areas across China has resulted in serious environmental problems such as groundwater pollution that originates from atmospheric, soil and water enrichment with reactive $\mathrm{N}$ of agricultural origin (Ju et al., 2009a; Yi et al., 2010). Studies indicate that the annual application of synthetic $\mathrm{N}$ for conventional agricultural practice in east and southeast China as well as the North China plain now ranges from 550 to $600 \mathrm{~kg}$ of N per hectare for typical double-cropping systems (Zhao et al., 2006; Zhu and Chen, 2002). The combined effects of large synthetic $\mathrm{N}$ fertilisers, rapid development of livestock production systems and rapidly increasing consumption of biofuels have severely disturbed regional biogeochemical $\mathrm{N}$ cycling across China, consequently resulting in environmental problems like eutrophication of surface waters, nitrate pollution of groundwater, acid rain and soil acidification, greenhouse gas emissions and diverse forms of air pollution (Guo et al., 2010; Ju et al., 2009b; Zhang et al., 2013). With this backdrop, excessive nitrate contamination of agricultural areas across China is a critical problem needing attention. Remote sensing has been shown to be an effective and cost-effective method of obtaining both spatial and temporal information required for fertiliser management (Moran et al., 1997; Yi et al., 2007). In particular, hyperspectral remote sensing can have a major contribution in understanding plant physiology (Jingfeng and Blackburn, 2011) and crop biochemical composition (Yi et al., 2007; Yi et al., 2010). For effective fertiliser management, tools capable of rapidly quantifying the nitrogen status of crops over large areas is essential (Yi et al., 2010). Though the use of satellite based hyperspectral instruments is limited for this application, results of studies performed using leaf, plant or canopy hyperspectral reflectance data can assist in the design of hyperspectral satellite sensors that can be utilised for this purpose. 
In the study by Yi et al. (2010), nitrogen concentration of rice on a canopy scale was estimated using hyperspectral reflectance data acquired over the wavelength range of 350 to $2500 \mathrm{~nm}$. Linear regression and artificial neural network (ANN) methods were applied for constructing predictive models and the results showed good agreement between observed and predicted $\mathrm{N}$ using both methods. However, the most effective method for estimating the rice nitrogen concentration was the PC-ANN (Principal Component - Artificial Neural Network). While the PC-ANN approach is most effective, it should be noted that this approach could be computing intensive the optimal number of hyperspectral PCs would be dependent on the nature of data used for analysis. Huang and Blackburn (2011) investigated the use of reflectance spectra (ranging from 400 to $2500 \mathrm{~nm}$ ) subjected to continuous wavelet analysis for estimating leaf chlorophyll (chl) concentration, a parameter that is frequently used to determine crop fertiliser requirement. Using the PROSPECT model, leaf reflectance spectra were simulated based on randomly selected values for input parameters. From the reflectance and first derivative spectra, different spectral wavelength domains were extracted and analysed using 53 different wavelets. The resulting wavelet coefficients, ranging from scales 1 to 128 were used as independent factors to construct predictive models for leaf chl concentrations.

The results showed lower scale wavelet coefficients (scales 1-32) contained little information on chl concentration while the higher scale wavelet coefficients (64-128) captured more information on chl concentration. The results also showed that the predictive capability increased rapidly when the spectral domains vary from 400-700 to 400-900 nm and fluctuated for broader domains. Hence, overall there is good evidence that hyperspectral remote sensing data combined with appropriate analytical techniques hold considerable potential for assessing crop fertiliser requirements.

\subsection{Optimising management responses to abiotic and biotic stress in crops}

A range of factors can induce physiological stress in crops which in turn results in reducing yield levels and agricultural productivity. The timely detection of stress in plants can be actualised by developing the capabilities of 'hyper-sensing' as demonstrated in the study by Liu et al. (2010). The authors utilised hyperspectral reflectance data to discriminate and classify different fungal infection levels in rice panicles using neural network and PCA techniques respectively. The reflectance spectra (400-2400nm) were smoothed with a five-step moving average to suppress instrumental and environmental noise. The spectra represented the domains of 400-2400nm for the raw and $\log 1 / \mathrm{R}$ spectra. The effective spectral regions of first and second derivative reflectance were ranges from $450 \mathrm{~nm}$ to $850 \mathrm{~nm}$ and from $500 \mathrm{~nm}$ to $800 \mathrm{~nm}$ respectively. The missing segments corresponding to strong instrument and environment noise were not considered for our analysis. Using a learning vector quantisation neural network, it was possible to classify healthy, light, moderate and serious infection levels. Results of the study showed potential for effectively discriminating different fungal infection levels of rice panicles under laboratory conditions while using hyperspectral data. Spectroscopic and imaging techniques are powerful disease monitoring methods that have been used to detect diseases caused by pests (Mahlein et al., 2012; Nansen et al., 2009) and nutrient stress in plants (Baret et al., 2007). The use of high spatial resolution satellite data can be also used for the accurate and timely detection of crop stress and determine the causal factors. A study conducted by She et al. (in prep)) used Chinese HJ multispectral sensors having high revisit times (4 days) to monitor freeze injury of winter oilseed rape in parts of China. This was based on the variations of NDVI values between post - and pre-disaster periods. In summary, combined or singular usage of high spectral or spatial resolution data is vital in providing plant physiological information needed for quantifying in optimising agricultural management responses. 


\subsection{Maximising yields while minimising water use in arid regions}

A major challenge of agriculture in North West (NW) China is the occurrence of desertification (Yang et al., 2005) which has negatively affected the crop yield in the region. In this context, there is potential for using remote sensing to improve the assessment of drought vulnerability in order to spatially and temporally optimise water-use efficiency in China (Kang et al., 2003). The utilisation of satellite derived vegetation indices to monitor crop conditions under natural disasters such as drought and frost (Kogan, 1995; Renhua et al., 2008; Xiaodong et al., 2012) is one of the ways forward in mitigating the threats of drought to high crop yields. Fang et al. (2010) stated that modelling and remote sensing could be used to evaluate and improve current agronomic management practices for increasing water use efficiency at field and regional scales. Do and Kang (2014) assessed drought vulnerability using soil moisture based water efficiency measures obtained from a variety of remote sensing satellite data in dryland regions across North East Asia. The study utilised AVHRR derived NDVI and soil moisture data from the Special Sensor Microwave Imager (SSM/I) to generate Soil Moisture Use Efficiency (SMUE). A MODIS derived land-cover map at $1 \mathrm{~km}$ spatial resolution was used to identify barren and grassland dominated pixels during analysis. The SMUE was used as a proxy in place of Water Use Efficiency (WUE) (DeLucia and Heckathorn, 1989; Reichstein et al., 2002) to evaluate drought vulnerability in North East Asia drylands from 1987 - 2006. Using the SMUE ratio and two additional SMUE derived indices (i.e. Drought Stress - DSI and Sensitivity - DVI) drought vulnerable regions were detected. This study demonstrates the applicability of the SMUE-based vulnerability indices for identifying drought vulnerability across wide geographic regions. The results showed both DSI and DVI flagged parts of midnorth China as areas of high drought vulnerability. The results further revealed that the vulnerable regions had experienced increased sand storm occurrence or land-degradation as reported in previous studies.

Overall, satellite data are useful means of evaluating the spatial and temporal dynamics of vegetation and biophysical variables. When combined from multiple sources, satellite data can be used to produce new information on relationships between different biophysical variables that a single satellite sensor is unable to capture (Do and Kang, 2014; Lewis et al., (submitted); Mo et al., 2005; Renhua et al., 2008). Satellite 'hyper-sensing' offers the potential of substantially increasing the range of biophysical variables related to drought vulnerability and the accuracy of retrievals, which can in turn improve the effectiveness of mitigation approaches. However, compared to the other application areas discussed previously, the use of 'hyper-sensing' in this area requires considerably further research.

\subsection{Large-scale crop/cropland mapping}

The availability of accurate and timely information regarding agricultural production is crucial in ensuring world food security. Hence, access to freely available medium-resolution satellite data (such as Sentinel and Landsat) offers possibility of improved global agricultural mapping and monitoring. The unique advantage of satellite observations is their synoptic and repetitive nature which in turn provides spatially contiguous information on crop growth at regional to global scales in a timely manner. Studies that have sucessful implemented global cropland mapping are usually dependent on a variety of available high spatial and temporal resolution satellite data (Fritz et al., 2015; Song et al., 2017). Fritz et al. (2015) produced a coarse $1 \mathrm{~km}$ global IIASA-IFPRI cropland percentage map by intergrating a number of individual cropland maps at global to regional to national scales. The individual map products include existing global land cover maps (such as GlobCover 2005 and MODIS v.5), regional maps (such as AFRICOVER) and national maps from mapping agencies and other organisations. In another study demonstrating the value of medium-resolution optical satellite data, Song et al. (2017) 
developed and tested a method for estimating in-season crop acreage using a probability sample of field visits and producing wall-to-wall soya crop type maps at national scales. This was performed using a stratified, two-stage cluster sampling design used to collect field data needed for estimating national soybean area. The soyabean cover maps were generated from Landsat image archive for the 2015 growing season using an active learning approach. The soyabean cover map overall accuracy was $84 \%$. The method developed in this study provided reliable and timely information on soybean area in a cost effective manner rather than ground based mapping. Shelestov et al. (2017) explored the efficiency of using the Google Earth Engine platform when classifying multi-temporal satellite imagery with potential to apply the platform for a larger scale (e.g., country level) and multiple sensors (e.g., Landsat-8 and Sentinel-2).

In a similar manner, the use of fine resolution SAR observations has become common practice as they are better suited to field-scale crop classification. The key advantage of intergrating SARs with optical data in crop classification is that microwave sensors are usually unaffected by cloud cover, thus making SARs a more reliable source of data for scientific and operational needs. The sucess of utilising SAR data for crop mapping is the avilability of high temporal coverage of microwave satellite imagery over crop growing season. The classification process is performed based on changes or variations in backscatter over time. Whilst selecting or determining the suitable number of images required for crop classification, a number of considertions need to be considered, namely the planting pratice, number of cropping system per year, and presence or absence of intercropping. Le Toan et al. (1997) used two ERS-1 SAR images acquired during the rice growth cycle, distict changes in the backscatter were sucessfully used to identify rice fields across the study area. By relating the backscatter responses to canopy height and biomass, the authors were able to map rice fields over different growth stages. In a similar study, it was discovered that the dynamic range of RADARSAT images, though lower than ERS-1 images exhibited potential potential for rice-mapping (Ribbes, 1999). The value of the Cosmo SkyMed spaceborne SAR satellites for rice field mapping using series of X-band images has been demonstrated in a number of studies (Bouvet et al., 2009; Chen et al., 2007a). Torbick et al. (2017b) mapped the spatial extent and established rice greenhouse gas emissions in the Red River Delta, Vietnam, using multiscale satellite imagery and a processed-based biogeochemical model. Multiscale SAR (Sentinel-1) and optical imagery (Landsat $8 \mathrm{OLI}$ ) were fed into a random forest classifier using field observations and surveys as training data to map rice extent.

\subsection{Management zone delineation}

The use of high spatial resolution spaceorne imagery has shown to provide valuable background detail for zonal management delination in precision agriculture application. Song et al. (2009) developed and compared different approaches of delinating management zones in a field of winter wheat. The soil and yield samples were collected and five main crop nutrients analysed (namely, total nitrogen, nitrate nitrogen, available phosphorus, extractable potassium and organic matter). Using QuickBird imagery acquired during the heading stage the optimised soil-adjusted vegetation index (OSAVI) was determined. With a fuzzy k-means clustering algorithm management zones were sucessfully classified. A total of three managment zones were identified in the study area. The management zones were delineated in three ways; based on soil and yield data, crop remote sensing information and the combination of soil, yield and remote sensing information. The results of this study suggest that management zone delineation using remote sensing data was reliable and feasible. Similarly, López-Granados (2011) recently reviewed the value of remote sensing to weed detection for site-specific weed management in real time. In the paper, the authors itemised some multispectral spaceborne sensors (such as IKONOS, QuickBird, and GeoEye-1) with the appropriate spatial resolution to detect and map 
weeds for site specific weed management. The authors emphasise the importance of remote sensing in generating accurate and timely weed maps of large scale weed infestations.

For effective management of agriculture fields, it is neceassary to map or 'zone' existing variations such as soil type, nutrient levels, soil-water, and topography. These zones can then be considered as management units in which profitability can be maximised based on variable rate applications guided by differential GPS and remote sensing products. Owing to nitrogen carry-over, nitrogen credits from previous crops need to be accounted for in determining the appropriate rate of fertiliser application for current crops (Hapka et al., 2000). Seelan et al. (2003) demonstrate the value of satellite imagery for zoning based on green tops derived from normalised difference vegetation index (NDVI) products derived from IKONOS imagery for fields with approximate area of 30 hectares. Using high spatial NDVI images fields where sugar beets were grown in the year 2000 were zoned for variable-rate application of nitrogen for the 2001 wheat crop. In comparison to conventional zoning methods of gridbased soil samples, the use of high-resolution spaceborne satellite imagery saved a total of US\$810 for the 30 ha field. In addition, the average fertriliser cost reduced by US $\$ 466$ per year while revenue from sale of sugar content increased by US\$6050 per year. Also, the variable-rate application resulted in an application of 35\% (i.e. $2900 \mathrm{~kg}$ ) less nitrogen which in turn reduced the effect of environmnetal pollution that would have occured if zononing was not performed. Bausch and Khosla (2010b) compared the nitrogen status of maize plants from QuickBird multispectral satellite data and a ground-based mobile radiometric system. In this study, several green waveband vegetation indices (such as green normalized difference vegetation index, $\mathrm{N}$ reflectance index, and chlorophyll index) for plant $\mathrm{N}$ status assessment between the two systems were compared. In conclusion, the study demonstrated QuickBird satellite multispectral data can adequately assess the $\mathrm{N}$ status of maize and its spatial variability within a field for in-season $\mathrm{N}$ management.

\section{Conclusions and future perspectives}

The utility of satellite 'hyper-sensing' for Chinese agriculture has been explored in this paper. It has demonstrated that the high temporal, spectral and spatial data have the potential to provide valuable inputs required for more effective agricultural monitoring which can be translated into effective management decision. However, for this potential to be realised it will be necessary to develop an effective system which integrates research, technological innovation and knowledge transfer together with existing operational systems. Figure 3 presents the potential structure of such a system and shows the three key stages in which the system could be developed. The basis of the approach (Fig.3 (1)) would be existing monitoring systems (such as CHARM (Chen et al., 2011c)) or CropWatch (Wu et al., 2013; Wu et al., 2010) that already have effective processing and information dissemination schemes. These established systems utilise existing satellite data (such as Landsat and MODIS), conventional data analysis techniques, conventional retrieval of crop parameters and interpretation techniques and dissemination of results through established governmental networks capable of transmitting information to farmers and stakeholders at all levels. Alongside this would be a system operating on novel approaches (Fig.3 (2), building on advances in science and technology (e.g. new sensors), innovation in data analysis techniques, advanced approaches to retrieving crop parameters and improvements in data dissemination methods. The key advantage of this parallel approach is that it allows for the integration into existing operational systems of new science and technology, as it emerges.

However, a step-change in yield sustainability in China can only be achieved if the proposed agricultural monitoring by remote sensing system can make a significant contribution to 
improved decision making and daily operations of local farmers and government. Therefore, forging a link between monitoring systems, science and regular agricultural activities is essential and this could be provided through agricultural extension programmes. By establishing experimental stations aimed at developing technologies to increase crop production across China, it would be possible to re-enforce the technical capacity of local farmers (Fig.3 (3). Consequently, the adoption of such technology would build a bridge between the local farmers and scientists. Programmes such as China's Science and Technology Backyard (Shen et al., 2013), which provides information and support to local farmers is valuable model that is worthy of adoption in this context. By integrating 'hyper-sensing' to China's agricultural sector in this way, there exists a strong opportunity to connect reliable remotely sensed products or proxies to farmers in order to support management decisions. This approach holds potential as a means of maximising crop yield whilst minimising resource inputs and environmental impacts and thereby achieving yield sustainability in China.

[Figure 3]

\section{Acknowledgements}

The publication was made possible through funding from the Science \& Technology Facilities (STFC) Newton Agri-Tech Fund Pathfinder Project (2014-15). The project titled 'Exploring satellite 'hyper-sensing' to deliver yield sustainability in China' involved collaborating partners from academia, research institutions and consultants based in China and the United Kingdom. Part of this work is supported by the National Natural Foundation of China (41471277).

\section{References}

Achard, F., Stibig, H.-J., Eva, H.D., Lindquist, E.J., Bouvet, A., Arino, O., Mayaux, P., 2010. Estimating tropical deforestation from Earth observation data. Carbon Management 1, 271-287. Anguela, T.P., Zribi, M., Baghdadi, N., Loumagne, C., 2010. Analysis of Local Variation of Soil Surface Parameters With TerraSAR-X Radar Data Over Bare Agricultural Fields. Geoscience and Remote Sensing, IEEE Transactions on 48, 874-881.

Aschbacher, J., Milagro-Pérez, M.P., 2012. The European Earth monitoring (GMES) programme: Status and perspectives. Remote Sensing of Environment 120, 3-8.

Ash, R.F., Edmonds, R.L., 1998. China's land resources, environment and agricultural production. The China Quarterly 156, 836-879.

Asner, G.P., 2001. Cloud cover in Landsat observations of the Brazilian Amazon. International Journal of Remote Sensing 22, 3855-3862.

Ban, Y., 2016. Multitemporal Remote Sensing: Current Status, Trends and Challenges, Multitemporal Remote Sensing. Springer, pp. 1-18.

Baret, F., Houlès, V., Guérif, M., 2007. Quantification of plant stress using remote sensing observations and crop models: the case of nitrogen management. J. Exp. Bot. 58, 869-880.

Bargiel, D., Herrmann, S., 2011. Multi-Temporal Land-Cover Classification of Agricultural Areas in Two European Regions with High Resolution Spotlight TerraSAR-X Data. Remote Sensing 3, 859877.

Battazza, F., Ciappa, A., Coletta, A., Costantini, M., Covello, F., Manoni, G., Minati, F., Pietranera, L., Valentini, G., 2012. COSMO-SkyMed mission: risk management applications over China, Myanmar and Haiti conducted during 2008. International journal of remote sensing 33, 4741-4755. Bausch, W., Khosla, R., 2010a. QuickBird satellite versus ground-based multi-spectral data for estimating nitrogen status of irrigated maize. Precision Agric 11, 274-290.

Bausch, W.C., Khosla, R., 2010b. QuickBird satellite versus ground-based multi-spectral data for estimating nitrogen status of irrigated maize. Precision Agric 11, 274-290. 
Becker-Reshef, I., Justice, C., Sullivan, M., Vermote, E., Tucker, C., Anyamba, A., Small, J., Pak, E., Masuoka, E., Schmaltz, J., Hansen, M., Pittman, K., Birkett, C., Williams, D., Reynolds, C., Doorn, B., 2010. Monitoring Global Croplands with Coarse Resolution Earth Observations: The Global Agriculture Monitoring (GLAM) Project. Remote Sensing 2, 1589-1609.

Belward, A.S., Skøien, J.O., 2015. Who launched what, when and why; trends in global land-cover observation capacity from civilian earth observation satellites. ISPRS Journal of Photogrammetry and Remote Sensing 103, 115-128.

Berger, M., Aschbacher, J., 2012. Preface: The Sentinel missions-new opportunities for science. Remote Sensing of Environment 120, 1-2.

Blaes, X., Vanhalle, L., Defourny, P., 2005. Efficiency of crop identification based on optical and SAR image time series. Remote Sensing of Environment 96, 352-365.

Boschetti, M., Stroppiana, D., Brivio, P.A., Bocchi, S., 2009. Multi-year monitoring of rice crop phenology through time series analysis of MODIS images. International Journal of Remote Sensing 30, 4643-4662.

Bouvet, A., Le Toan, T., Lam-Dao, N., 2009. Monitoring of the rice cropping system in the Mekong Delta using ENVISAT/ASAR dual polarization data. IEEE Transactions on Geoscience and Remote Sensing 47, 517-526.

Byoung-Sun, L., Yoola, H., Ok-Cheol, J., Jae-Cheol, Y., 2011. Orbit maintenance for calibration of KOMPSAT-5, Synthetic Aperture Radar (APSAR), 2011 3rd International Asia-Pacific Conference on, pp. 1-5.

Cai, X., Cui, Y., 2009. Crop planting structure extraction in irrigated areas from multi-sensor and multi-temporal remote sensing data. Transactions of the Chinese Society of Agricultural Engineering $25,124-130$.

CEH, 2016. CEH Land Cover Plus: Crops 2015. Centre for Ecology \& Hydrology.

CEOS, 2015. The Earth Observation Handbook.

Chai, X., Zhang, T., Shao, Y., Gong, H., Liu, L., Xie, K., 2015. Modeling and mapping soil moisture of plateau pasture using RADARSAT-2 imagery. Remote Sensing 7, 1279-1299.

Chen, J., Huang, J., Hu, J., 2011a. Mapping rice planting areas in southern China using the China Environment Satellite data. Mathematical and Computer Modelling 54, 1037-1043.

Chen, J., Jönsson, P., Tamura, M., Gu, Z., Matsushita, B., Eklundh, L., 2004. A simple method for reconstructing a high-quality NDVI time-series data set based on the Savitzky-Golay filter. Remote sensing of Environment 91, 332-344.

Chen, J., Lin, H., Pei, Z., 2007a. Application of ENVISAT ASAR data in mapping rice crop growth in Southern China. IEEE Geoscience and Remote Sensing Letters 4, 431-435.

Chen, Q., Li, Z., Wang, L., 2005. AN ANALYSIS OF APPLYING S-BAND SAR OF HJ-1C TO SOIL MOISTURE CHANGE RETRIEVAL [J]. Remote Sensing For Land \& Resources 2.

Chen, Y., Jiang, J., Jing, G., Li, J., 2007b. Analysis of hyperspectral characters of winter wheat under different nitrogen and water stress, Geoscience and Remote Sensing Symposium, 2007. IGARSS 2007. IEEE International, pp. 3031-3034.

Chen, Z., Zhou, Q., Liu, J., Wang, L., Ren, J., Huang, Q., Deng, H., Zhang, L., Li, D., 2011 b. Charms-China Agricultural Remote Sensing Monitoring System, Geoscience and Remote Sensing Symposium (IGARSS), 2011 IEEE International. IEEE, pp. 3530-3533.

Chen, Z.X., Zhou, Q.B., Liu, J., Wang, L.M., Ren, J.Q., Huang, Q., Deng, H., Zhang, L., Li, D.D., 2011c. Charms - China Agricultural Remote Sensing Monitoring System, Geoscience and Remote Sensing Symposium (IGARSS), 2011 IEEE International, pp. 3530-3533.

China Import Export, 2014. China Rice Imports Reach Record High. China Import Export.

Clark, M.L., Roberts, D.A., 2012. Species-Level Differences in Hyperspectral Metrics among Tropical Rainforest Trees as Determined by a Tree-Based Classifier. Remote Sensing 4, 1820-1855. Clauss, K., Yan, H., Kuenzer, C., 2016. Mapping Paddy Rice in China in 2002, 2005, 2010 and 2014 with MODIS Time Series. Remote Sensing 8, 434.

Clevers, J.G.P.W., van Leeuwen, H.J.C., 1996. Combined use of optical and microwave remote sensing data for crop growth monitoring. Remote Sensing of Environment 56, 42-51.

Coltri, P.P., Zullo, J., Gonçalves, R., Romani, L.A., Pinto, H.S., 2012a. Carbon stock estimation in coffee crops using high resolution satellites, Geoscience and Remote Sensing Symposium (IGARSS), 2012 IEEE International. IEEE, pp. 6657-6660. 
Coltri, P.P., Zullo, J., Goncalves, R.R.V., Romani, L.A.S., Pinto, H.S., 2012b. Carbon stock estimation in coffee crops using high resolution satellites, Geoscience and Remote Sensing Symposium (IGARSS), 2012 IEEE International, pp. 6657-6660.

Corcione, V., Nunziata, F., Mascolo, L., Migliaccio, M., 2016. A study of the use of COSMOSkyMed SAR PingPong polarimetric mode for rice growth monitoring. International Journal of Remote Sensing 37, 633-647.

Costa, M.H., Foley, J.A., 1998. A comparison of precipitation datasets for the Amazon basin. Geophysical Research Letters 25, 155-158.

Covello, F., Battazza, F., Coletta, A., Lopinto, E., Fiorentino, C., Pietranera, L., Valentini, G., Zoffoli, S., 2010. COSMO-SkyMed an existing opportunity for observing the Earth. Journal of Geodynamics $49,171-180$

Dadhwal, V.K., Sing, R.P., Dutta, S., Parihar, J.S., 2002. Remote sensing based crop inventory: A review of Indian experience. Tropical Ecology 43, 107-122.

Delbart, N., Emmanuelle, V., Fabienne, M., Catherine, O., Jean-Marc, G., 2017. Combining optical remote sensing, agricultural statistics and field observations for culture recognition over a Peri-urban region, EGU General Assembly Conference Abstracts, p. 3585.

Delegido, J., Verrelst, J., Alonso, L., Moreno, J., 2011. Evaluation of sentinel-2 red-edge bands for empirical estimation of green LAI and chlorophyll content. Sensors 11, 7063-7081.

DeLucia, E.H., Heckathorn, S.A., 1989. The effect of soil drought on water-use efficiency in a contrasting Great Basin desert and Sierran montane species. Plant, Cell \& Environment 12, 935-940.

Ding, C., 2003. Land policy reform in China: assessment and prospects. Land use policy 20, 109-120. Do, N., Kang, S., 2014. Assessing drought vulnerability using soil moisture-based water use efficiency measurements obtained from multi-sensor satellite data in Northeast Asia dryland regions. Journal of Arid Environments 105, 22-32.

Dong, J., Xiao, X., Kou, W., Qin, Y., Zhang, G., Li, L., Jin, C., Zhou, Y., Wang, J., Biradar, C., Liu, J., Moore Iii, B., 2015. Tracking the dynamics of paddy rice planting area in 1986-2010 through time series Landsat images and phenology-based algorithms. Remote Sensing of Environment 160, 99-113. Dong, J., Xiao, X., Menarguez, M.A., Zhang, G., Qin, Y., Thau, D., Biradar, C., Moore, B., 2016. Mapping paddy rice planting area in northeastern Asia with Landsat 8 images, phenology-based algorithm and Google Earth Engine. Remote Sensing of Environment 185, 142-154.

Drusch, M., Del Bello, U., Carlier, S., Colin, O., Fernandez, V., Gascon, F., Hoersch, B., Isola, C., Laberinti, P., Martimort, P., Meygret, A., Spoto, F., Sy, O., Marchese, F., Bargellini, P., 2012. Sentinel-2: ESA's Optical High-Resolution Mission for GMES Operational Services. Remote Sensing of Environment 120, 25-36.

Du, J., Shi, J., Sun, R., 2010a. The development of HJ SAR soil moisture retrieval algorithm. International Journal of Remote Sensing 31, 3691-3705.

Du, J.Y., Shi, J.C., Sun, R.J.S., 2010b. The development of HJ SAR soil moisture retrieval algorithm. International Journal of Remote Sensing 31, 3691-3705.

Duk-jin, K., 2011. Monitoring of coastal wind and oil spill using KOMPSAT-5, Synthetic Aperture Radar (APSAR), 2011 3rd International Asia-Pacific Conference on, pp. 1-4.

El Hajj, M., Bégué, A., Guillaume, S., Martiné, J.-F., 2009. Integrating SPOT-5 time series, crop growth modeling and expert knowledge for monitoring agricultural practices - The case of sugarcane harvest on Reunion Island. Remote Sensing of Environment 113, 2052-2061.

Esch, T., Metz, A., Marconcini, M., Keil, M., 2014. Combined use of multi-seasonal high and medium resolution satellite imagery for parcel-related mapping of cropland and grassland. International Journal of Applied Earth Observation and Geoinformation 28, 230-237. Evans, D.L., 2006. Spaceborne imaging radar-C/X-band synthetic aperture radar (SIR-C/X-SAR): a look back on the tenth anniversary. IEE Proceedings -- Radar, Sonar \& Navigation 153, 81-85. Ewing, J.J., Zhang, H., 2013. China as the World's Largest Rice Importer: Regional Implications, in: reliefweb (Ed.).

Fan, M.S., Shen, J.B., Yuan, L.X., Jiang, R.F., Chen, X.P., Davies, W.J., Zhang, F.S., 2012. Improving crop productivity and resource use efficiency to ensure food security and environmental quality in China. J. Exp. Bot. 63, 13-24. 
Fang, Q.X., Ma, L., Green, T.R., Yu, Q., Wang, T.D., Ahuja, L.R., 2010. Water resources and water use efficiency in the North China Plain: Current status and agronomic management options.

Agricultural Water Management 97, 1102-1116.

FAO, 2014. FAOSTAT database: agricultural production. Food and Agriculture Organisation of the United Nations - Statistics Division, Rome.

Feng, W., Yao, X., Zhu, Y., Tian, Y.C., Cao, W.X., 2008. Monitoring leaf nitrogen status with hyperspectral reflectance in wheat. European Journal of Agronomy 28, 394-404.

Fieuzal, R., Marais Sicre, C., Baup, F., 2017. Estimation of corn yield using multi-temporal optical and radar satellite data and artificial neural networks. International Journal of Applied Earth

Observation and Geoinformation 57, 14-23.

Fontana, D.C., Melo, R.W., Wagner, A.P.L., Weber, E., Gusso, A., 2006. Use of Remote Sensing for Crop Yield and Area Estimates in the Southern of Brazil, Paper presented in Workshop Remote Sensing Support to Crop Yield and Area Estimates. JRC/ISPRS, Stresa, Italy.

Fred, G., Hansen, J., Jewison, M., 2014. China's Growing Demand for Agricultural Imports, U.S. Department of Agriculture, Economic Research Service.

Fritz, S., See, L., McCallum, I., You, L., Bun, A., Moltchanova, E., Duerauer, M., Albrecht, F., Schill, C., Perger, C., 2015. Mapping global cropland and field size. Global change biology 21, 1980-1992. Galford, G.L., Mustard, J.F., Melillo, J., Gendrin, A., Cerri, C.C., Cerri, C.E., 2008. Wavelet analysis of MODIS time series to detect expansion and intensification of row-crop agriculture in Brazil. Remote sensing of environment 112, 576-587.

Gao, F., Anderson, M.C., Zhang, X., Yang, Z., Alfieri, J.G., Kustas, W.P., Mueller, R., Johnson, D.M., Prueger, J.H., 2017. Toward mapping crop progress at field scales through fusion of Landsat and MODIS imagery. Remote Sensing of Environment 188, 9-25.

Gao, F., Masek, J., Schwaller, M., Hall, F., 2006. On the blending of the Landsat and MODIS surface reflectance: Predicting daily Landsat surface reflectance. IEEE Transactions on Geoscience and Remote sensing 44, 2207-2218.

Gibbons, G., 2000. Turning a farm art into science-an overview of precision farming. URL: http://www. precisionfarming. com.

Gitelson, A.A., 2013. Remote estimation of crop fractional vegetation cover: the use of noise equivalent as an indicator of performance of vegetation indices. International Journal of Remote Sensing 34, 6054-6066.

Gommes, R., Wu, B., Li, Z., Zeng, H., 2015. Design and characterization of spatial units for monitoring global impacts of environmental factors on major crops and food security. Food and Energy Security.

Gommes, R., Wu, B., Zhang, N., Feng, X., Zeng, H., Li, Z., Chen, B., 2017. CropWatch agroclimatic indicators (CWAIs) for weather impact assessment on global agriculture. International Journal of Biometeorology 61, 199-215.

Gonsamo, A., 2010. Leaf area index retrieval using gap fractions obtained from high resolution satellite data: Comparisons of approaches, scales and atmospheric effects. International Journal of Applied Earth Observation and Geoinformation 12, 233-248.

Guo, H.D., 2012. China's Earth observing satellites for building a Digital Earth. International Journal of Digital Earth 5, 185-188.

Guo, J.H., Liu, X.J., Zhang, Y., Shen, J.L., Han, W.X., Zhang, W.F., Christie, P., Goulding, K.W.T., Vitousek, P.M., Zhang, F.S., 2010. Significant Acidification in Major Chinese Croplands. Science 327, 1008-1010.

Guo, Y., Shi, Z., Li, H., Triantafilis, J., 2013. Application of digital soil mapping methods for identifying salinity management classes based on a study on coastal central China. Soil Use and Management 29, 445-456.

Haboudane, D., Miller, J.R., Pattey, E., Zarco-Tejada, P.J., Strachan, I.B., 2004. Hyperspectral vegetation indices and novel algorithms for predicting green LAI of crop canopies: Modeling and validation in the context of precision agriculture. Remote Sensing of Environment 90, 337-352.

Hapka, A., Franzen, D., Giles, J., Cattanach, N., 2000. Timing and release of nitrogen from residues. Sugarbeet Research and Extension Reports, Minnesota and North Dakota Sugarbeet Research and Education Board 31, 114-121. 
Harmon, T., Kvien, C., Mulla, D., Hoggenboom, G., Judy, J., Hook, J., 2005. Precision agriculture scenario, in: Arzberger, P. (Ed.), NSF workshop on sensors for environmental observatories. World Tech. Evaluation Center, Baltimore, MD, USA.

Harrell, P.A., Kasischke, E.S., Bourgeau-Chavez, L.L., Haney, E.M., Christensen Jr, N.L., 1997. Evaluation of approaches to estimating aboveground biomass in Southern pine forests using SIR-C data. Remote Sensing of Environment 59, 223-233.

He, C., Liu, Z., Xu, M., Ma, Q., Dou, Y., 2017. Urban expansion brought stress to food security in China: Evidence from decreased cropland net primary productivity. Science of The Total Environment 576, 660-670.

Hoang, K.H., Bernier, M., Duchesne, S., Tran, M.Y., 2011. Identification of rice fields in a complex land-use region using RADARSAT-2 data, Synthetic Aperture Radar (APSAR), 2011 3rd International Asia-Pacific Conference on, pp. 1-4.

Hornacek, M., Wagner, W., Sabel, D., Hong-Linh, T., Snoeij, P., Hahmann, T., Diedrich, E., Doubkova, M., 2012. Potential for High Resolution Systematic Global Surface Soil Moisture Retrieval via Change Detection Using Sentinel-1. Selected Topics in Applied Earth Observations and Remote Sensing, IEEE Journal of 5, 1303-1311.

Hu, L.Y., Chen, Y.L., Xu, Y., Zhao, Y.Y., Yu, L., Wang, J., Gong, P., 2014. A 30 meter land cover mapping of China with an efficient clustering algorithm CBEST. Science China: Earth Sciences 57, 2293-2304.

Hua, X., Pierce, L.E., Dobson, M.C., Ulaby, F.T., 1998. Combining orbital SAR and optical data for global classification, Geoscience and Remote Sensing Symposium Proceedings, 1998. IGARSS '98. 1998 IEEE International, pp. 1599-1601 vol.1593.

Huang, Q., Zhang, L., Wu, W., Li, D., 2010. MODIS-NDVI-Based crop growth monitoring in China Agriculture Remote Sensing Monitoring System, Geoscience and Remote Sensing (IITA-GRS), 2010 Second IITA International Conference on, pp. 287-290.

Huang, S., Miao, Y., Yuan, F., Gnyp, M.L., Yao, Y., Cao, Q., Wang, H., Lenz-Wiedemann, V.I., Bareth, G., 2017. Potential of RapidEye and WorldView-2 Satellite Data for Improving Rice Nitrogen Status Monitoring at Different Growth Stages. Remote Sensing 9, 227.

Immitzer, M., Atzberger, C., Koukal, T., 2012. Tree Species Classification with Random Forest Using Very High Spatial Resolution 8-Band WorldView-2 Satellite Data. Remote Sensing 4, 2661-2693. Islam, K., Jashimuddin, M., Nath, B., Nath, T.K., (in press). Land use classification and change detection by using multi-temporal remotely sensed imagery: The case of Chunati wildlife sanctuary, Bangladesh. The Egyptian Journal of Remote Sensing and Space Science.

Jia, K., Li, Q., Tian, Y., Wu, B., Zhang, F., Meng, J., 2012. Crop classification using multiconfiguration SAR data in the North China Plain. International Journal of Remote Sensing 33, 170183.

Jia, K., Wu, B., Li, Q., 2013. Crop classification using HJ satellite multispectral data in the North China Plain. Journal of Applied Remote Sensing 7, 073576-073576.

Jiao, X., Kovacs, J.M., Shang, J., McNairn, H., Walters, D., Ma, B., Geng, X., 2014. Object-oriented crop mapping and monitoring using multi-temporal polarimetric RADARSAT-2 data. ISPRS Journal of Photogrammetry and Remote Sensing 96, 38-46.

Jingfeng, H., Blackburn, G.A., 2011. Optimizing predictive models for leaf chlorophyll concentration based on continuous wavelet analysis of hyperspectral data. International Journal of Remote Sensing 32, 9375-9396.

Jonsson, P., Eklundh, L., 2004. TIMESAT - a program for analyzing time-series of satellite sensor data. Computers and Geosciences 30, 833-845.

Jönsson, P., Eklundh, L., 2004. TIMESAT - a program for analyzing time-series of satellite sensor data. Computers \& Geosciences 30, 833-845.

Joshi, N., Baumann, M., Ehammer, A., Fensholt, R., Grogan, K., Hostert, P., Jepsen, M., Kuemmerle, T., Meyfroidt, P., Mitchard, E., Reiche, J., Ryan, C., Waske, B., 2016. A Review of the Application of Optical and Radar Remote Sensing Data Fusion to Land Use Mapping and Monitoring. Remote Sensing 8, 70 .

Ju, X.-T., Xing, G.-X., Chen, X.-P., Zhang, S.-L., Zhang, L.-J., Liu, X.-J., Cui, Z.-L., Yin, B., Christie, P., Zhu, Z.-L., Zhang, F.-S., 2009a. Correction for Ju et al., Reducing environmental risk by 
improving N management in intensive Chinese agricultural systems. Proceedings of the National Academy of Sciences 106, 8077.

Ju, X.-T., Xing, G.-X., Chen, X.-P., Zhang, S.-L., Zhang, L.-J., Liu, X.-J., Cui, Z.-L., Yin, B., Christie, P., Zhu, Z.-L., Zhang, F.-S., 2009b. Reducing environmental risk by improving N management in intensive Chinese agricultural systems. Proceedings of the National Academy of Sciences 106, 3041-3046.

Kang, S., Davies, W., Shan, L., Cai, H., 2003. Water-saving agriculture and sustainable use of water and land resources. Shaanxi Science and Technology Press, Xian, PR China.

Kang, S., Hao, X., Du, T., Tong, L., Su, X., Lu, H., Li, X., Huo, Z., Li, S., Ding, R., 2017. Improving agricultural water productivity to ensure food security in China under changing environment: From research to practice. Agricultural Water Management 179, 5-17.

Kerr, J.T., Ostrovsky, M., 2003. From space to species: ecological applications for remote sensing. Trends in Ecology \& Evolution 18, 299-305.

Kim, S.R., Lee, W.K., Kwak, H.B., Choi, S.H., 2009. Estimating carbon sequestration in forest using KOMPSAT-2 imagery. Journal of Korean Forestry Society.

Kogan, F.N., 1995. Application of vegetation index and brightness temperature for drought detection. Advances in Space Research 15, 91-100.

Korporal, K.D., Dobbins, R., Hillary, N.M., 1989. The Statistics Canada Crop Condition Assessment Program, Geoscience and Remote Sensing Symposium, 1989. IGARSS'89. 12th Canadian

Symposium on Remote Sensing., 1989 International, pp. 2006-2009.

Kramer, H.J., Cracknell, A.P., 2008. An overview of small satellites in remote sensing. International Journal of Remote Sensing 29, 4285-4337.

Kressler, F.P., Kim, Y.S., Steinnocher, K.T., 2003. Object-oriented land cover classification of panchromatic KOMPSAT-1 and SPOT-5 data, Geoscience and Remote Sensing Symposium, 2003. IGARSS '03. Proceedings. 2003 IEEE International, pp. 3471-3473 vol.3476.

Krieger, G., Moreira, A., 2006. Spaceborne bi- and multistatic SAR: potential and challenges. IEEE Proceedings - Radar, Sonar \& Navigation 153, 184-198.

Kurosu, T., Fujita, M., Chiba, K., 1995. Monitoring of rice crop growth from space using the ERS-1 C-band SAR. Geoscience and Remote Sensing, IEEE Transactions on 33, 1092-1096.

Kussul, N., Skakun, S., Shelestov, A., Kravchenko, O., Kussul, O., 2012. Crop classification in Ukraine using satellite optical and SAR images. Inf. Models Anal 2, 118-122.

Lavender, S., 2016. MONITORING LAND COVER DYNAMICS AT VARYING SPATIAL

SCALES USING HIGH TO VERY HIGH RESOLUTION OPTICAL IMAGERY. ISPRS-

International Archives of the Photogrammetry, Remote Sensing and Spatial Information Sciences, 937-939.

Le Toan, T., Ribbes, F., Li-Fang, W., Floury, N., Kung-Hau, D., Jin Au, K., Fujita, M., Kurosu, T., 1997. Rice crop mapping and monitoring using ERS-1 data based on experiment and modeling results. IEEE Transactions on Geoscience and Remote Sensing 35, 41-56.

Lee, J.-W., Park, G., Joh, H.-K., Lee, K.-H., Na, S.-I., Park, J.-H., Kim, S.-J., 2011. Analysis of Relationship between Vegetation Indices and Crop Yield using KOMPSAT (KOreaMulti-Purpose SATellite)-2 Imagery and Field Investigation Data. Journal of the Korean Society of Agricultural Engineers 53, 75-82.

Leichtle, T., Geiß, C., Wurm, M., Lakes, T., Taubenböck, H., 2017. Unsupervised change detection in VHR remote sensing imagery - an object-based clustering approach in a dynamic urban environment. International Journal of Applied Earth Observation and Geoinformation 54, 15-27.

Lewinski, S., Bochenek, Z., Turlej, K., 2010. Application of object-oriented method for classification of VHR satellite images using rule-based approach and texture measures. Geoinformation Issues 2, 2. Lewis, A.R., Blackburn, G.A., \& , Theobald, J.C., (submitted). A multi-sensor approach for crop irrigation scheduling: thermal, spectral, fluorescence and LIDAR remote sensing of plant responses to drought and re-watering. Agricultural and Forest Meteorology.

Li, F., Miao, Y., Feng, G., Yuan, F., Yue, S., Gao, X., Liu, Y., Liu, B., Ustin, S.L., Chen, X., 2014a. Improving estimation of summer maize nitrogen status with red edge-based spectral vegetation indices. Field Crops Research 157, 111-123.

Li, F., Mistele, B., Hu, Y., Yue, X., Yue, S., Miao, Y., Chen, X., Cui, Z., Meng, Q., Schmidhalter, U., 2012a. Remotely estimating aerial N status of phenologically differing winter wheat cultivars grown 
in contrasting climatic and geographic zones in China and Germany. Field Crops Research 138, 21 32.

Li, J.S., Zhang, B., Shen, Q., Zhou, L., Li, L.W., 2012b. Monitoring water quality of Lake Taihu from HJ-CCD data using empirical models, Geoscience and Remote Sensing Symposium (IGARSS), 2012 IEEE International, pp. 812-815.

Li, L., Friedl, M.A., Xin, Q.C., Gray, J., Pan, Y.Z., Frolking, S., 2014b. Mapping Crop Cycles in China Using MODIS-EVI Time Series. Remote Sensing 6, 2473-2493.

Li, L., Luo, H., Zhu, H.H., 2014c. Estimation of the Image Interpretability of ZY-3 Sensor Corrected Panchromatic Nadir Data. Remote Sensing 6, 4409-4429.

Li, X., Pan, Y., Zhao, C., Wang, J., Bao, Y., Wang, J., 2005. Delineation and scale effect of precision agriculture management zones using yield monitor data over four years. Scientia Agricultura Sinica $38,1825-1833$.

Li, Y., Gong, J.H., Wang, D.C., An, L.P., Li, R., 2013. Sloping farmland identification using hierarchical classification in the Xi-He region of China. International Journal of Remote Sensing 34, 545-562.

Li, Y., Shi, Z., Wu, C., Li, F., Cheng, J., 2007. Definition of management zones based on fuzzy clustering analysis in coastal saline land. Scientia Agricultura Sinica 40, 114-122.

Lichtenberg, E., Ding, C., 2008. Assessing farmland protection policy in China. Land Use Policy 25, 59-68.

Lin, L., Luo, H., Zhu, H., Li, Z., Tang, X.M.T., 2013. User-oriented image quality assessment of ZY3 product in agriculture area, Agro-Geoinformatics (Agro-Geoinformatics), 2013 Second International Conference on, pp. 22-27.

Liping, Y., Hong, C., Wenjiang, T., 2007. Study on crop estimation method based on SPOT high resolution remote sensing data. Journal of Anhui Agricultural Sciences 35, 7054.

Liu, C., Shang, J., Vachon, P.W., McNairn, H., 2013. Multiyear crop monitoring using polarimetric RADARSAT-2 data. IEEE Transactions on Geoscience and Remote sensing 51, 2227-2240.

Liu, Z.-Y., Wu, H.-F., Huang, J.-F., 2010. Application of neural networks to discriminate fungal infection levels in rice panicles using hyperspectral reflectance and principal components analysis. Computers and Electronics in Agriculture 72, 99-106.

Long, D.G., Hardin, P.J., 1994. Vegetation studies of the Amazon basin using enhanced resolution Seasat scatterometer data. IEEE Transactions on Geoscience and Remote Sensing 32, 449-460. Long, D.G., Hardin, P.J., Whiting, P.T., 1993. Resolution enhancement of spaceborne scatterometer data. IEEE Transactions on Geoscience and Remote Sensing 31, 700-715.

López-Granados, F., 2011. Weed detection for site-specific weed management: mapping and real-time approaches. Weed Research 51, 1-11.

Lu, D., Mausel, P., Brondizio, E., Moran, E., 2004. Change detection techniques. International journal of remote sensing 25, 2365-2401.

Mahfouf, J.-F., 2010. Assimilation of satellite-derived soil moisture from ASCAT in a limited-area NWP model. Quarterly Journal of the Royal Meteorological Society 136, 784-798.

Mahlein, A.-K., Steiner, U., Hillnhutter, C., Dehne, H.-W., Oerke, E.-C., 2012. Hyperspectral imaging for small-scale analysis of symptoms caused by different sugar beet diseases. Plant Methods 8, 3 .

Mansaray, L.R., Huang, W., Zhang, D., Huang, J., Li, J., 2017. Mapping Rice Fields in Urban

Shanghai, Southeast China, Using Sentinel-1A and Landsat 8 Datasets. Remote Sensing 9, 257.

McNairn, H., Brisco, B., 2004. The application of C-band polarimetric SAR for agriculture: a review. Canadian Journal of Remote Sensing 30, 525-542.

McNairn, H., Champagne, C., Shang, J., Holmstrom, D., Reichert, G., 2009a. Integration of optical and Synthetic Aperture Radar (SAR) imagery for delivering operational annual crop inventories. ISPRS Journal of Photogrammetry and Remote Sensing 64, 434-449.

McNairn, H., Merzouki, A., Pacheco, A., Fitzmaurice, J., 2012. Monitoring soil moisture to support risk reduction for the agriculture sector using RADARSAT-2. IEEE Journal of Selected Topics in Applied Earth Observations and Remote Sensing 5, 824-834.

McNairn, H., Shang, J., Champagne, C., Jiao, X., 2009b. TerraSAR-X and RADARSAT-2 for crop classification and acreage estimation, Geoscience and Remote Sensing Symposium,2009 IEEE International,IGARSS 2009, pp. II-898-II-901. 
Mei, A., Manzo, C., Fontinovo, G., Bassani, C., Allegrini, A., Petracchini, F., 2016. Assessment of land cover changes in Lampedusa Island (Italy) using Landsat TM and OLI data. Journal of African Earth Sciences 122, 15-24.

Meng, J.H., Wu, B.F., Li, Q.Z., Du, X., 2009. Monitoring crop phenology with MERIS data - A case study of winter wheat in North China Plain, Progress In Electromagnetics Research Symposium, Beijing, China.

Merzouki, A., McNairn, H., Pacheco, A., 2011. Mapping soil moisture using RADARSAT-2 data and local autocorrelation statistics. IEEE Journal of Selected Topics in Applied Earth Observations and Remote Sensing 4, 128-137.

Middleton, E.M., Ungar, S.G., Mandl, D.J., Ong, L., Frye, S.W., Campbell, P.E., Landis, D.R., Young, J.P., Pollack, N.H., 2013. The Earth Observing One (EO-1) Satellite Mission: Over a Decade in Space. Selected Topics in Applied Earth Observations and Remote Sensing, IEEE Journal of 6, 243-256.

Mo, X., Liu, S., Lin, Z., Xu, Y., Xiang, Y., McVicar, T.R., 2005. Prediction of crop yield, water consumption and water use efficiency with a SVAT-crop growth model using remotely sensed data on the North China Plain. Ecological Modelling 183, 301-322.

MOA, 2015. China's No.1 Central Document focuses on agriculture for 12th consecutive year. Ministry of Agriculture of the Peoples's Republic of China.

Moran, M.S., Inoue, Y., Barnes, E.M., 1997. Opportunities and limitations for image-based remote sensing in precision crop management. Remote Sensing of Environment 61, 319-346.

Mulla, D.J., 2013. Twenty five years of remote sensing in precision agriculture: Key advances and remaining knowledge gaps. Biosystems engineering 114, 358-371.

Nansen, C., Macedo, T., Swanson, R., Weaver, D.K., 2009. Use of spatial structure analysis of hyperspectral data cubes for detection of insect-induced stress in wheat plants. International Journal of Remote Sensing 30, 2447-2464.

Nguyen, D.B., Gruber, A., Wagner, W., 2016. Mapping rice extent and cropping scheme in the Mekong Delta using Sentinel-1A data. Remote Sensing Letters 7, 1209-1218.

Novelli, A., Aguilar, M.A., Nemmaoui, A., Aguilar, F.J., Tarantino, E., 2016. Performance evaluation of object based greenhouse detection from Sentinel-2 MSI and Landsat 8 OLI data: A case study from Almería (Spain). International Journal of Applied Earth Observation and Geoinformation 52, 403 411.

Onojeghuo, A.O., Blackburn, G.A., 2011. Optimising the use of hyperspectral and LiDAR data for mapping reedbed habitats. Remote Sensing of Environment 115, 2025-2034.

Ortenberg, F., 2011. Hyperspectral Sensor Characteristics, in: Thenkabail, P.S., Lyon, J.G., Huete, A. (Eds.), Hyperspectral Remote Sensing of Vegetation. CRC Press, pp. 39-68.

Palmann, C., Mavromatis, S., Hernandez, M., Sequeira, J., Brisco, B., 2008. Earth observation using radar data: an overview of applications and challenges. International Journal of Digital Earth 1, 171195.

Pan, G., Sun, G.-J., Li, F.-M., 2009. Using QuickBird imagery and a production efficiency model to improve crop yield estimation in the semi-arid hilly Loess Plateau, China. Environmental Modelling \& Software 24, 510-516.

Pan, Z.K., Huang, J.F., Zhou, Q.B., Wang, L.M., Cheng, Y.X., Zhang, H.K., Blackburn, G.A., Yan, J., Liu, J.H., 2015. Mapping crop phenology using NDVI time-series derived from HJ-1 A/B data. International Journal of Applied Earth Observation and Geoinformation 34, 188-197. Panigrahy, S., Chakraborty, M., Sharma, S.A., Kundu, N., Ghose, S.C., Pal, M., 1997. Early estimation of rice area using temporal ERS-1 synthetic aperature radar data - a acase study for the Howrah and Hughly districts of West Bengal, India. International Journal of Remote Sensing 18, 1827-1833.

Park, S., Im, J., Park, S., Rhee, J., 2017. Drought monitoring using high resolution soil moisture through multi-sensor satellite data fusion over the Korean peninsula. Agricultural and Forest Meteorology 237, 257-269.

Pearlman, J., Carman, S., Segal, C., Jarecke, P., Clancy, P., Browne, W., 2001. Overview of the Hyperion Imaging Spectrometer for the NASA EO-1 mission, Geoscience and Remote Sensing Symposium, 2001. IGARSS '01. IEEE 2001 International, pp. 3036-3038 vol.3037. 
Peng, D., Huete, A.R., Huang, J., Wang, F., Sun, H., 2011. Detection and estimation of mixed paddy rice cropping patterns with MODIS data. International Journal of Applied Earth Observation and Geoinformation 13, 13-23.

Piao, S., Ciais, P., Huang, Y., Shen, Z., Peng, S., Li, J., Zhou, L., Liu, H., Ma, Y., Ding, Y., Friedlingstein, P., Liu, C., Tan, K., Yu, Y., Zhang, T., Fang, J., 2010. The impacts of climate change on water resources and agriculture in China. Nature 467, 43-51.

Pinzon, J., Tucker, C., 2014. A Non-Stationary 1981-2012 AVHRR NDVI3g Time Series. Remote Sensing 6, 6929.

$\mathrm{Pu}, \mathrm{R}$., Bell, S., 2013. A protocol for improving mapping and assessing of seagrass abundance along the West Central Coast of Florida using Landsat TM and EO-1 ALI/Hyperion images. ISPRS Journal of Photogrammetry and Remote Sensing 83, 116-129.

$\mathrm{Pu}, \mathrm{R}$., Gong, P., 2011. Hyperspectral remote sensing of vegetation bioparameters, in: Thenkabail, P.S., Lyon, J.G., Huete, A. (Eds.), Advances in environmental remote sensing: Sensors, algorithms, and applications, pp. 101-142.

Qiu, B., Fan, Z., Zhong, M., Tang, Z., Chen, C., 2014. A new approach for crop identification with wavelet variance and JM distance. Environ Monit Assess 186, 7929-7940.

Ramirez, G.M., Zullo Jr, J., 2010. Estimation of biophysical parameters of coffee fields based on high-resolution satellite images. Engenharia Agricola 30, 468-479.

Ramoelo, A., Cho, M.A., Mathieu, R., Madonsela, S., Van De Kerchove, R., Kaszta, Z., Wolff, E., 2015. Monitoring grass nutrients and biomass as indicators of rangeland quality and quantity using random forest modelling and WorldView-2 data. International Journal of Applied Earth Observation and Geoinformation 43, 43-54.

Reichert, G.C., Caissy, D., 2002. A Reliable Crop Condition Assessment Program (CCAP) Incorporating NOAA AVHRR Data, a Geographical Information System and the Internet.

Reichstein, M., Tenhunen, J.D., Roupsard, O., Ourcival, J.-m., Rambal, S., Miglietta, F., Peressotti, A., Pecchiari, M., Tirone, G., Valentini, R., 2002. Severe drought effects on ecosystem CO2 and H2O fluxes at three Mediterranean evergreen sites: revision of current hypotheses? Global Change Biology 8, 999-1017.

Ren, J., Chen, Z., Zhou, Q., Tang, H., 2008. Regional yield estimation for winter wheat with MODISNDVI data in Shandong, China. International Journal of Applied Earth Observation and Geoinformation 10, 403-413.

Renhua, Z., Hongbo, S., Jing, T., Zhaoliang, L., Shaohui, C., Jinyan, Z., Xiangzheng, D., Xiaomin, S., Jianjun, W., 2008. Drought Monitoring in Northern China based on Remote Sensing Data and Land Surface Modeling, Geoscience and Remote Sensing Symposium, 2008. IGARSS 2008. IEEE International, pp. III - 860-III - 863.

Ribbes, F., 1999. Rice field mapping and monitoring with RADARSAT data. International Journal of Remote Sensing 20, 745-765.

SAC, 1995. Manual for crop production forecasting using spaceborne remotely sensed data. a joint project of Space and Ministry of Agriculture, Govt. of India.

Sakamoto, T., Yokozawa, M., Toritani, H., Shibayama, M., Ishitsuka, N., Ohno, H., 2005. A crop phenology detection method using time-series MODIS data. Remote sensing of environment 96, 366374.

Sanchez, N., Martinez-Fernandez, J., Piles, M., Camps, A., Vall-llossera, M., Aguasca, A., 2014. Hyperspectral-derived indices for soil moisture estimation at very high resolution, Geoscience and Remote Sensing Symposium (IGARSS), 2014 IEEE International, pp. 2898-2901.

Sandholt, I., 2001. The combination of polarimetric SAR with satellite SAR and optical data for classification of agricultural land. Geografisk Tidsskrift-Danish Journal of Geography 101, 21-32. Sang-Ryool, L., 2010. Overview of KOMPSAT-5 program, mission, and system, Geoscience and Remote Sensing Symposium (IGARSS), 2010 IEEE International, pp. 797-800.

Sankaran, S., Mishra, A., Ehsani, R., Davis, C., 2010. A review of advanced techniques for detecting plant diseases. Computers and Electronics in Agriculture 72, 1-13.

Santi, E., Fontanelli, G., Montomoli, F., Brogioni, M., Macelloni, G., Paloscia, S., Pettinato, S., Pampaloni, P., 2012. The retrieval and monitoring of vegetation parameters from COSMO-SkyMed images, Geoscience and Remote Sensing Symposium (IGARSS), 2012 IEEE International. IEEE, pp. 7031-7034. 
Savitzky, A., Golay, M.J., 1964. Smoothing and differentiation of data by simplified least squares procedures. Analytical chemistry 36, 1627-1639.

Sawaya, K.E., Olmanson, L.G., Heinert, N.J., Brezonik, P.L., Bauer, M.E., 2003. Extending satellite remote sensing to local scales: land and water resource monitoring using high-resolution imagery.

Remote Sensing of Environment 88, 144-156.

Schafer, R.W., 2011. What Is a Savitzky-Golay Filter? [Lecture Notes]. IEEE Signal Processing Magazine 28, 111-117.

Seelan, S.K., Laguette, S., Casady, G.M., Seielstad, G.A., 2003. Remote sensing applications for precision agriculture: A learning community approach. Remote Sensing of Environment 88, 157-169. She, B., Huang, J., Guo, R., Blackburn, G.A., \&, Wang, H.B., Wang, J., in prep. Application of high temporal resolution satellite data for monitoring freezing injury in oilseed rape. International Journalof Applied Earth Observation and Geoinformatics.

Shelestov, A., Lavreniuk, M., Kussul, N., Novikov, A., Skakun, S., 2017. Exploring Google Earth Engine Platform for Big Data Processing: Classification of Multi-Temporal Satellite Imagery for Crop Mapping. Frontiers in Earth Science 5.

Shen, G., Xu, B., Jin, Y., Chen, S., Zhang, W., Guo, J., Liu, H., Zhang, Y., Yang, X., 2017. Monitoring wind farms occupying grasslands based on remote-sensing data from China's GF-2 HD satellite-A case study of Jiuquan city, Gansu province, China. Resources, Conservation and Recycling 121, 128-136.

Shen, J., Cui, Z., Miao, Y., Mi, G., Zhang, H., Fan, M., Zhang, C., Jiang, R., Zhang, W., Li, H., 2013. Transforming agriculture in China: From solely high yield to both high yield and high resource use efficiency. Global Food Security 2, 1-8.

Shin, J., Lee, K., Kim, J., 2010. Field test of KOMPSAT-5 Calibration Equipment, Geoscience and Remote Sensing Symposium (IGARSS), 2010 IEEE International, pp. 805-807.

Shu-cheng, Y., Shun-xi, L., Zong-xue, X., 2011. Evaluation on high spatial resolution SAR data for land use discrimination and land change detection. Chinese Agricultural Science Bulletin 8, 090. Sibanda, M., Mutanga, O., Rouget, M., 2016. Discriminating Rangeland Management Practices Using Simulated HyspIRI, Landsat 8 OLI, Sentinel 2 MSI, and VEN $\mu$ S Spectral Data. IEEE Journal of Selected Topics in Applied Earth Observations and Remote Sensing 9, 3957-3969.

Singh, D., Prakash, R., Pathak, N.P., Mohan, S., Singh, K.P., 2011. SAR and optical data utilization for soil moisture retrieval in vegetated region, Synthetic Aperture Radar (APSAR), 2011 3rd International Asia-Pacific Conference on, pp. 1-4.

Smil, V., 1999. China's agricultural land. The China Quarterly 158, 414-429.

Son, N.T., Chen, C.F., Chen, C.R., Minh, V.Q., 2017. Assessment of Sentinel-1A data for rice crop classification using random forests and support vector machines. Geocarto International, 1-15. Song, H., Huang, B., 2013. Spatiotemporal satellite image fusion through one-pair image learning. IEEE Transactions on Geoscience and Remote Sensing 51, 1883-1896.

Song, X.-P., Potapov, P.V., Krylov, A., King, L., Di Bella, C.M., Hudson, A., Khan, A., Adusei, B., Stehman, S.V., Hansen, M.C., 2017. National-scale soybean mapping and area estimation in the United States using medium resolution satellite imagery and field survey. Remote Sensing of Environment 190, 383-395.

Song, X., Wang, J., Huang, W., Liu, L., Yan, G., Pu, R., 2009. The delineation of agricultural management zones with high resolution remotely sensed data. Precision Agric 10, 471-487.

Soria-Ruiz, J., Fernandez-Ordoñez, Y., Woodhouse, I.H., 2010. Land-cover classification using radar and optical images: a case study in Central Mexico. International Journal of Remote Sensing 31, 3291-3305.

Steele-Dunne, S.C., McNairn, H., Monsivais-Huertero, A., Judge, J., Liu, P.W., Papathanassiou, K., 2017. Radar Remote Sensing of Agricultural Canopies: A Review. IEEE Journal of Selected Topics in Applied Earth Observations and Remote Sensing 10, 2249-2273.

Stroppiana, D., Boschetti, M., Brivio, P.A., Bocchi, S., 2009. Plant nitrogen concentration in paddy rice from field canopy hyperspectral radiometry. Field Crops Research 111, 119-129.

Tan, M., Li, X., Xie, H., Lu, C., 2005. Urban land expansion and arable land loss in China-a case study of Beijing-Tianjin-Hebei region. Land use policy 22, 187-196.

Tang, X., Xie, J., 2012. Overview of the key technologies for high-resolution satellite mapping.

International Journal of Digital Earth 5, 228-240. 
Teng, F., Chen, Z.X., Wu, W.B., Huang, Q., Li, D.D., Tian, X., 2012. Yield estimation of winter wheat in North China Plain by using crop growth monitoring system (CGMS), Agro-Geoinformatics (Agro-Geoinformatics), 2012 First International Conference on, pp. 1-4.

Thenkabail, P., Gumma, M.K., Teluguntla, P., Irshad, A.M., 2014. Hyperspectral Remote Sensing of Vegetation and Agricultural Crops. Photogrammetric Engineering and Remote Sensing 80, 697-709. Thenkabail, P.S., Mariotto, I., Gumma, M.K., Middleton, E.M., Landis, D.R., Huemmrich, K.F., 2013. Selection of Hyperspectral Narrowbands (HNBs) and Composition of Hyperspectral Twoband Vegetation Indices (HVIs) for Biophysical Characterization and Discrimination of Crop Types Using Field Reflectance and Hyperion/EO-1 Data. Selected Topics in Applied Earth Observations and Remote Sensing, IEEE Journal of 6, 427-439.

Tian, X., Chen, E., Li, Z.Y., Su, Z.B., Ling, F.1., Bai, L.N., Wu, F.Y., 2010. Comparison of crop classification capabilities of spaceborne multi-parameter SAR data, Geoscience and Remote Sensing Symposium (IGARSS), 2010 IEEE International, pp. 359-362.

Torbick, N., Chowdhury, D., Salas, W., Qi, J., 2017a. Monitoring Rice Agriculture across Myanmar Using Time Series Sentinel-1 Assisted by Landsat-8 and PALSAR-2. Remote Sensing 9, 119.

Torbick, N., Salas, W., Chowdhury, D., Ingraham, P., Trinh, M., 2017b. Mapping rice greenhouse gas emissions in the Red River Delta, Vietnam. Carbon Management 8, 99-108.

Tsai, F., Lin, E.K., Yoshino, K., 2007. Spectrally segmented principal component analysis of hyperspectral imagery for mapping invasive plant species. International Journal of Remote Sensing 8, 1023-1039.

Turker, M., Ozdarici, A., 2011. Field-based crop classification using SPOT4, SPOT5, IKONOS and QuickBird imagery for agricultural areas: a comparison study. International Journal of Remote Sensing 32, 9735-9768.

Varvel, G.E., Schepers, J.S., Francis, D.D., 1997. Ability for in-season correction of nitrogen deficiency in corn using chlorophyll meters. Soil Science Society of America Journal 61, 1233-1239. Vyas, S.P., Steven, M.D., Jaggard, K.W., Xu, H., 2003. Comparison of sugar beet crop cover estimates from radar and optical data. International Journal of Remote Sensing 24, 1071.

Wagner, W., Pathe, C., Doubkova, M., Sabel, D., Bartsch, A., Hasenauer, S., Blöschl, G., Scipal, K., Martínez-Fernández, J., Löw, A., 2008. Temporal Stability of Soil Moisture and Radar Backscatter Observed by the Advanced Synthetic Aperture Radar (ASAR). Sensors 8, 1174.

Wang, D., Lin, H., Chen, J., Zhang, Y., Zeng, Q., 2010a. Application of multi-temporal ENVISAT ASAR data to agricultural area mapping in the Pearl River Delta. International Journal of Remote Sensing 31, 1555-1572.

Wang, D., Xu, Z., Zhao, J., Wang, Y., Yu, Z., 2011. Excessive nitrogen application decreases grain yield and increases nitrogen loss in a wheat-soil system. Acta Agriculturae Scandinavica, Section BSoil \& Plant Science 61, 681-692.

Wang, J., Huang, J., Zhang, K., Li, X., She, B., Wei, C., Gao, J., Song, X., 2015a. Rice Fields Mapping in Fragmented Area Using Multi-Temporal HJ-1A/B CCD Images. Remote Sensing 7, 3467-3488.

Wang, J., Huang, J.F., Wang, X.Z., Jin, M.T., Zhou, Z., Guo, Q.Y., Zhao, Z.W., Huang, W.J., Zhang, Y., Song, X.D., 2015b. Estimation of rice phenology date using integrated HJ-1 CCD and Landsat-8 OLI vegetation indices time-series images. Journal of Zhejiang University-SCIENCE B (Biomedicine \& Biotechnology) 16, 832-844.

Wang, L., Wang, C., Hao, P., Shi, K., Abdullah, A., 2014. Cotton area estimation using muti-sensor RS data and big plot survey in Xinjiang, Agro-geoinformatics (Agro-geoinformatics 2014), Third International Conference on, pp. 1-5.

Wang, L., Yang, S., Xi, X., Li, W., 2009. Applications of Small Satellite Constellation for Environment and Disaster Monitoring and Forecastring (SSCEDMF) in Disaster Monitoring and Assessment, ISPRS, International Conference on Geo-spatial Solutions for Emergency Management and the 50th Anniversary of the Chinese Academy of Surveying and Mapping, Beijing, China. Wang, Q., 2012. Technical system design and construction of China's HJ-1 satellites. International Journal of Digital Earth 5, 202-216.

Wang, Q., Blackburn, G.A., Onojeghuo, A.O., Dash, J., Zhou, L., Zhang, Y., Atkinson, P.M., 2017. Fusion of Landsat 8 OLI and Sentinel-2 MSI Data. IEEE Transactions on Geoscience and Remote Sensing. 
Wang, Q., Wu, C., Li, Q., Li, J., 2010b. Chinese HJ-1A/B satellites and data characteristics. Sci. China Earth Sci. 53, 51-57.

Wang, X.L., Wang, G., Guan, Y., ChenG, Q., Gao, L.R., 2005. Small satellite constellation for disaster monitoring in China, Geoscience and Remote Sensing Symposium, 2005. IGARSS '05. Proceedings. 2005 IEEE International, p. 3 pp.

Wei, X., Declan, C., Erda, L., Yinlong, X., Hui, J., Jinhe, J., Ian, H., Yan, L., 2009. Future cereal production in China: the interaction of climate change, water availability and socio-economic scenarios. Global Environmental Change 19, 34-44.

White, M.A., Nemani, R.R., 2006. Real-time monitoring and short-term forecasting of land surface phenology. Remote Sensing of Environment 104, 43-49.

Wu, B.-f., Xu, W.-b., Sun, M., Li, Q.-z., Huang, H.-p., 2004. QuickBird imagery for crop pattern mapping. J. Remote Sens 8, 688-695.

$\mathrm{Wu}, \mathrm{B}$., Li, Q., 2012. Crop planting and type proportion method for crop acreage estimation of complex agricultural landscapes. International Journal of Applied Earth Observation and

Geoinformation 16, 101-112.

Wu, B.F., Meng, J.H., Li, Q.Z., Yan, N.N., Du, X., Zhang, M., 2013. Remote sensing-based global crop monitoring: experiences with China's CropWatch system. International Journal of Digital Earth 7, 113-137.

Wu, B.F., Meng, J.H., Li, Q.Z., Zhang, F.F., Du, X., Yan, N.N., 2010. Latest Development of CropWatch: A Global Crop Monitoring System with Remote Sensing. Advances in Earth Science 25, 1013 - 1022 (in Chinese with English Abstract).

Wu, J., Xia, H., Liu, Y., Caicong, W., 2005. Management the disaster in China from space technology, Geoscience and Remote Sensing Symposium, 2005. IGARSS '05. Proceedings. 2005 IEEE International, pp. 1620-1623.

Xiang, L.I., Yu-chun, P.A.N., Zhong-qiang, G.E., Chun-jiang, Z., 2007. Delineation and Scale Effect of Precision Agriculture Management Zones Using Yield Monitor Data Over Four Years. Agricultural Sciences in China 6, 180-188.

Xiaodong, W., Yansheng, D., Jianwei, Y., Hongping, C., 2012. Testing crop stress by MODIS vegetation index in the north China plain, Geoscience and Remote Sensing Symposium (IGARSS), 2012 IEEE International, pp. 6597-6600.

Xin-Zhong, W., Guo-Shun, L., Hong-Chao, H., Zhen-Hai, W., Qing-Hua, L., Xu-Feng, L., Wei-Hong, H., Yan-Tao, L., 2009. Determination of management zones for a tobacco field based on soil fertility. Computers and Electronics in Agriculture 65, 168-175.

Xinhua, 2015. China to speed up agri modernaization through reforms, innovations.

ChinaDaily.Com.Cn.

Xu, X., Cheng, T., Yao, X., Tian, Y., Zhu, Y., Cao, W., 2016. Mapping rice planting area from Landsat 8 imagery using one-class support vector machine, 2016 Fifth International Conference on Agro-Geoinformatics (Agro-Geoinformatics), pp. 1-5.

Xue, Y., Li, Y., Guang, J., Zhang, X., Guo, J., 2008. Small satellite remote sensing and applications history, current and future. International Journal of Remote Sensing 29, 4339-4372.

Yang, C., Everitt, J., Bradford, J., 2006. Comparison of QuickBird Satellite Imagery and Airborne Imagery for Mapping Grain Sorghum Yield Patterns. Precision Agric 7, 33-44.

Yang, C., Everitt, J.H., Murden, D., 2011. Evaluating high resolution SPOT 5 satellite imagery for crop identification. Computers and Electronics in Agriculture 75, 347-354.

Yang, H., Li, X., 2000. Cultivated land and food supply in China. Land use policy 17, 73-88.

Yang, X., Zhang, K., Jia, B., Ci, L., 2005. Desertification assessment in China: An overview. Journal of Arid Environments 63, 517-531.

Yi, Q.-X., Huang, J.-F., Wang, F.-M., Wang, X.-Z., Liu, Z.-Y., 2007. Monitoring Rice Nitrogen Status Using Hyperspectral Reflectance and Artificial Neural Network. Environmental Science \& Technology 41, 6770-6775.

Yi, Q., Huang, J., Wang, F.M., Wang, X.Z., 2010. Evaluating the performance of PC-ANN for the estimation of rice nitrogen concentration from canopy hyperspectral reflectance. International Journal of Remote Sensing 31, 931-940.

Yisok, O., Soon-Gu, K., Ji-Hwan, H., 2010. Soil moisture detection using KOMPSAT-5 SAR data, Geoscience and Remote Sensing Symposium (IGARSS), 2010 IEEE International, pp. 1250-1253. 
Yisok, O., Soon-Gu, K., Ji-Hwan, H., 2011. Soil moisture detection algorithm at X-band, Synthetic Aperture Radar (APSAR), 2011 3rd International Asia-Pacific Conference on, pp. 1-4.

Yonezawa, C., Negishi, M., Azuma, K., Watanabe, M., Ishitsuka, N., Ogawa, S., Saito, G., 2012. Growth monitoring and classification of rice fields using multitemporal RADARSAT-2 fullpolarimetric data. International Journal of Remote Sensing 33, 5696-5711.

Yoon, J.C., Keum, J.H., Shin, J.M., Kim, J.H., Lee, S.R., Bauleo, A., Farina, C., Germani, C., Mappini, M., Venturini, R., 2011. KOMPSAT-5 SAR design and performance, Synthetic Aperture Radar (APSAR), 2011 3rd International Asia-Pacific Conference on, pp. 1-4.

Yuan, F., Sawaya, K.E., Loeffelholz, B.C., Bauer, M.E., 2005. Land cover classification and change analysis of the Twin Cities (Minnesota) Metropolitan Area by multitemporal Landsat remote sensing. Remote Sensing of Environment 98, 317-328.

Yusoff, N.M., Muharam, F.M., Takeuchi, W., Darmawan, S., Abd Razak, M.H., 2017. Phenology and classification of abandoned agricultural land based on ALOS-1 and 2 PALSAR multi-temporal measurements. International Journal of Digital Earth 10, 155-174.

Zakzeski, A., Rosevelt, C., Melton, F., Johnson, L., Verdin, J., Thenkabail, P., Jones, J., 2013. Tracking Fallow Land in California Using USDA's Cropland Data Layer, AGU Fall Meeting Abstracts.

Zhang, B., Chen, Z.C., Li, J., Gao, L.R., 2009a. Image quality evaluation on Chinese first earth observation hyperspectral satellite. Geoscience and Remote Sensing Symposium,2009 IEEE International,IGARSS 2009 1, I-188-I-191.

Zhang, G., Xiao, X., Biradar, C.M., Dong, J., Qin, Y., Menarguez, M.A., Zhou, Y., Zhang, Y., Jin, C., Wang, J., Doughty, R.B., Ding, M., Moore Iii, B., 2017. Spatiotemporal patterns of paddy rice croplands in China and India from 2000 to 2015. Science of The Total Environment 579, 82-92.

Zhang, J., Shen, K., Pan, Y., Li, L., Hou, D., 2010. HJ-1 Remotely Sensed Data and Sampling Method for Wheat Area Estimation. Scientia Agricultura Sinica 43, 3306-3315.

Zhang, N., Wang, M., Wang, N., 2002. Precision agriculture - a worldwide overview. Computers and electronics in agriculture 36, 113-132.

Zhang, W.-f., Dou, Z.-x., He, P., Ju, X.-T., Powlson, D., Chadwick, D., Norse, D., Lu, Y.-L., Zhang, Y., Wu, L., Chen, X.-P., Cassman, K.G., Zhang, F.-S., 2013. New technologies reduce greenhouse gas emissions from nitrogenous fertilizer in China. Proceedings of the National Academy of Sciences $110,8375-8380$.

Zhang, X., Friedl, M.A., Schaaf, C.B., Strahler, A.H., Hodges, J.C.F., Gao, F., Reed, B.C., Huete, A., 2003. Monitoring vegetation phenology using MODIS. Remote Sensing of Environment 84, 471-475. Zhang, Y., Wang, C., Wu, J., Qi, J., Salas, W.A., 2009b. Mapping paddy rice with multitemporal ALOS/PALSAR imagery in southeast China. International journal of Remote sensing 30, 6301-6315. Zhao, J., Luo, Q., Deng, H., Yan, Y., 2008. Opportunities and challenges of sustainable agricultural development in China.

Zhao, R.-F., Chen, X.-P., Zhang, F.-S., Zhang, H., Schroder, J., Römheld, V., 2006. Fertilization and Nitrogen Balance in a Wheat-Maize Rotation System in North China. Agron. J. 98, 938-945.

Zheng, F.T., 2015. Farming methods have to change for good. ChinaDaily.Com.Cn.

Zhou, Y., Xiao, X., Qin, Y., Dong, J., Zhang, G., Kou, W., Jin, C., Wang, J., Li, X., 2016. Mapping paddy rice planting area in rice-wetland coexistent areas through analysis of Landsat 8 OLI and MODIS images. International Journal of Applied Earth Observation and Geoinformation 46, 1-12. Zhu, L., Radeloff, V.C., Ives, A.R., 2017. Improving the mapping of crop types in the Midwestern U.S. by fusing Landsat and MODIS satellite data. International Journal of Applied Earth Observation and Geoinformation 58, 1-11.

Zhu, Y., Yao, X., Tian, Y., Liu, X., Cao, W., 2008. Analysis of common canopy vegetation indices for indicating leaf nitrogen accumulations in wheat and rice. International Journal of Applied Earth Observation and Geoinformation 10,1-10.

Zhu, Z., Fu, Y., Woodcock, C.E., Olofsson, P., Vogelmann, J.E., Holden, C., Wang, M., Dai, S., Yu, Y., 2016. Including land cover change in analysis of greenness trends using all available Landsat 5, 7, and 8 images: A case study from Guangzhou, China (2000-2014). Remote Sensing of Environment $185,243-257$. 
Zhu, Z.L., Chen, D.L., 2002. Nitrogen fertilizer use in China - Contributions to food production, impacts on the environment and best management strategies. Nutrient Cycling in Agroecosystems 63, $117-127$ 